\title{
Extraction and modification of cellulose nanofibers derived from biomass for environmental application
}

\author{
Mridula Prakash Menon, ${ }^{\text {a }}$ R. Selvakumar, (D) *a Palaniswamy Suresh kumar (D) *b \\ and Seeram Ramakrishna (iD *c
}

Cellulose is a natural biopolymer that is abundantly available in plant cell walls and is secreted in its pure forms by many bacteria. Due to their unique features cellulose materials are considered as efficient replacements for conventional polymers. Cellulose nanofibers (CNF) have attracted wide interest due to their nano size, ease of preparation, low cost, tuneable surface properties and enhanced mechanical properties. However, the efficiency of CNF depends on the extraction method employed from its source and their features vary from source to source. Hence, there is a need to understand the specificity of CNF extraction from its source in order to obtain highly efficient CNF with maximum potential. CNF has been extracted from plant sources using physical, chemical and enzymatic methods. Although plant derived CNF possess excellent features, the involvement of chemicals and complexity in extraction process limits their usage. Bacterial CNF overcome this limitation through its extracellular secretion which makes extraction easy. CNF is also extracted from various marine filamentous algae. The percentage of CNF obtained from algal sources is less compared to plants and bacterial sources. CNF finds wide variety of applications such as drug carriers, tissue regenerating scaffolds, water purifying

${ }^{a}$ Nanobiotechnology Laboratory, PSG Institute of Advanced Studies, Coimbatore, India-641004. E-mail: selvabiotech@gmail.com

${ }^{b}$ Environmental \& Water Technology Centre of Innovation (EWTCOI), Ngee Ann Polytechnic, Singapore-599489. E-mail: sureshinphy@yahoo.com
${ }^{c}$ Center for Nanofibers and Nanotechnology, Department of Mechanical Engineering, National University of Singapore, Singapore 117576. E-mail: seeram@nus.edu.sg

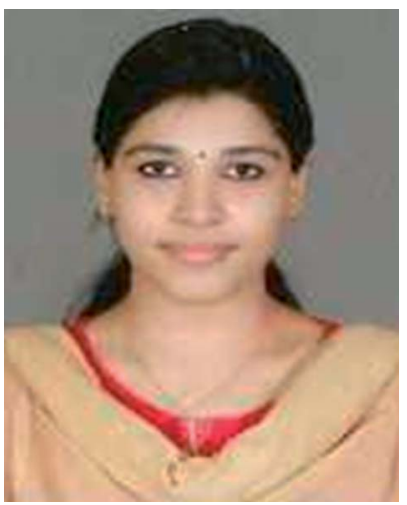

Ms. Mridula Prakash Menon is presently working as a PhD Research Scholar in the Nanobiotechnology laboratory at PSG Institute of Advanced Studies, Coimbatore, Tamil Nadu, India. She has completed her Masters in Biotechnology and M.Phil. in Nanoscience and Technology at PSG Institute of Advanced Studies. Her research interests include synthesis of nanomaterials for biomedical and environmental applications, microbial biotechnology, water purification, and bioremediation and drug delivery.

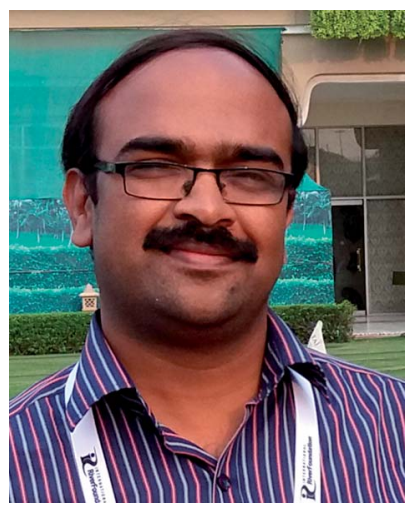

Dr R. Selvakumar is an Associate Professor in Nanobiotechnology at PSG Institute of Advanced Studies, Coimbatore, Tamil Nadu, India. He is currently working in the Department of Civil Engineering, Scott Engineering Centre, University of Nebraska, USA for his Water Advanced Research and Innovation (WARI) Fellowship awarded by INDO-US Science and Technology Forum, India. He is also a recipient of a prestigious Endeavour Research Fellow awarded by Ministry of Education, Goverment of Australia and a Blaustein postdoctoral fellowship award at Zuckerberg Institute for Water Research, Israel. He has 47 publications leading to 396 citations. His research interests include Water purification and effluent treatment using microorganism and nanomaterials, Nano biotechnology, Extremophilic microbiology, and Meniscal tissue engineering. 
membranes, electrodes, supercapacitors, fluorescent probes and flexible electronics. In this review, various extraction techniques of CNF from different plant and bacterial sources are discussed critically with special emphasis on CNF based composites.

\section{Introduction}

Cellulose (chemical formula: $\left.\left(\mathrm{C}_{6} \mathrm{H}_{10} \mathrm{O}_{5}\right)_{n}\right)$, the most abundant renewable polysaccharides in plants and microorganisms is composed of repeating units of $\beta$-D-glucopyranose bound through covalent linkage between the $\mathrm{OH}$ group of $\mathrm{C} 4$ and $\mathrm{C} 1$ carbon atoms. ${ }^{1,2}$ Based on its source, the obtained cellulose exhibits a characteristic structural hierarchy that can be interrupted using suitable extraction procedures to obtain various forms of cellulose. ${ }^{3,4}$ For more information about the details of structure, source, properties and various forms of cellulose, please refer to Moon et al. ${ }^{5}$ The properties of natural cellulose structures like shape, length and diameter depend on its origin and the extraction process. Hence variations in cellulosic properties are more likely and need individual study on cellulose derived from different plants. ${ }^{6}$ Despite various advantages, natural cellulose fibres exhibit few limitations that restrict its widespread applications such as poor thermal stability, noncompatibility with hydrophobic polymers, absorption of moisture etc. $^{7,8}$ Due to these limitations, there is a requirement of converting readily available cellulose into nano/micro-cellulosic forms or blending it with appropriate polymers to form composites which can enhance their desired properties. When compared to cellulosic microfibrils, nanoform of cellulose has high surface-to-volume value and nano-scale size effect that makes it superior. ${ }^{9}$ Cellulose extracted from plants $^{3}$ and

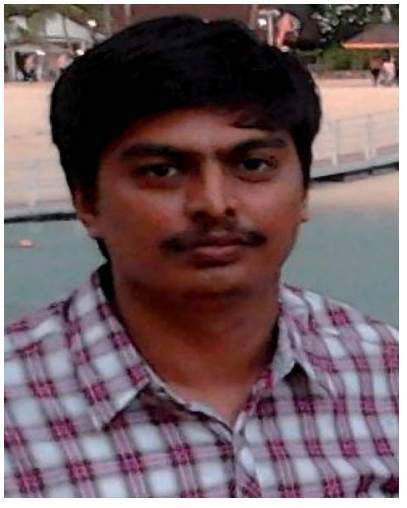

Dr Palaniswamy Suresh Kumar works as a Research \& Development Scientist at the Environmental and Water Technology Centre of Innovation (EWTCOI), Ngee Ann Polytechnic, Singapore. He received his $P h D$ in Physics from Department of Physics, Bharathiar University, India. In the same year, he joined as a Postdoctoral Fellow at School of Materials Science and Engineering \& Energy Research Institute@NTU (ERI@N), Nanyang Technological University (NTU), Singapore (2010-2013). He has authored and co-authored more than 60 peer-reviewed international publications with 2200 citations and $27 \mathrm{H}$-index. His core research is in Synthesis and Fabrication of $1 D$ Nanorods, Nanostructured Thin films, Smart self-Cleaning Coatings, Electrospun nanofibers for Energy and Environment Application.

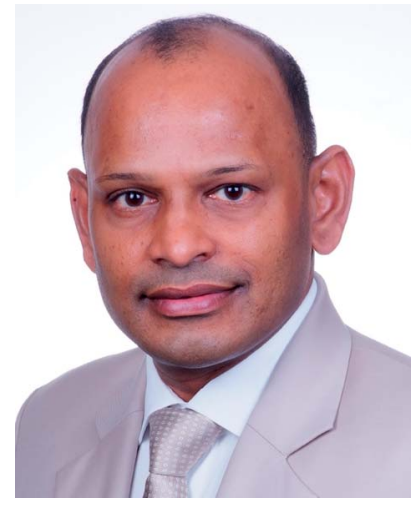

Professor Seeram Ramakrishna, FREng works at the National University of Singapore (NUS), which is ranked as the number one university in Asia and among the top universities in the world. He is a member of the World Economic Forum (WEF) Committee on Future of Production. He pioneered nanotechnology in Singapore. He is a Highly Cited Researcher in Materials Science (Clarivate Analytics). Thomson Reuters identified him among the World's most influential scientific minds. A European study (http:// www.webometrics.info/en/node/58) placed him among the only five researchers from Singapore with an $H$ index over 100, and among the only 1612 highly cited researchers $(H>100)$ in the world. He received his $P h D$ from the University of Cambridge, UK, and The General Management Training from the Harvard University, USA. He is an elected Fellow of UK Royal Academy of Engineering (FREng); Singapore Academy of Engineering; Indian National Academy of Engineering; and ASEAN Academy of Engineering \& Technology. He is an elected Fellow of International Union of Societies of Biomaterials Science and Engineering (FBSE); Institution of Engineers Singapore; ISTE, India; Institution of Mechanical Engineers and Institute of Materials, Minerals \& Mining, UK; and American Association of the Advancement of Science; ASM International; American Society for Mechanical Engineers; American Institute for Medical \& Biological Engineering, USA. His academic leadership includes University VicePresident (Research Strategy); Dean of Faculty of Engineering; Director of NUS Enterprise; Director of NUS Industry Liaison Office; Founding Director of NUS Bioengineering; Founding CoDirector of NUS Nanoscience \& Nanotechnology Initiative, NUSNNI; and Founding Chairman of Solar Energy Research Institute of Singapore, SERIS. 
secreted by microorganism ${ }^{10}$ have been converted into various nanostructures like nanofibers, ${ }^{11}$ hydrogels,${ }^{10}$ nanoparticles, ${ }^{5}$ aerogels,${ }^{12}$ films,${ }^{5}$ nanocrystals,${ }^{13}$ nanowhiskers ${ }^{14}$ etc. Among the various nanostructures derived from cellulose, cellulosic nanofibers have been widely investigated due to its excellent mechanical strength, flexibility, possibility of functionalization and blending, biodegradability, chirality, thermostability and low thermal expansion. Cellulose nanofibers (CNF) has been considered as potential matrix for various applications like optoelectronic conversion, energy storage, packaging, drug delivery, bioimaging and biomedical materials, nanofillers, protective coatings, barrier membranes and filtration media, transparent films, antimicrobial activity, pharmaceuticals etc. ${ }^{5,15,16} \mathrm{CNFs}$ are renewable, low cost and low density material with less abrasive property. ${ }^{17}$

The properties of CNF such as purity, biocompatibility, crystallinity, wettability and surface tuneable structure have intense effect on various environmental applications. Biocompatibility of CNF is an important property that makes them highly suitable for various biomedical applications especially in scaffold development for tissue engineering. This is also an important property for its environmental applications. ${ }^{18}$ As filtration system or membranes for water purification, the CNF should not degrade and release toxic materials that make the treated water unfit for human consumption. Highly pure CNFs are important in environmental aspect. This is due to the fact that, increase in CNF purity enhances the thermal stability of the fibers. This is especially important in applications such as sensor fabrication and catalytic decomposition of various pollutants in waste water remediation where thermal stability of CNFs is highly demanded. In catalytic decomposition, the CNF acts as catalyst and prevent the aggregation of nanoparticles such as $\mathrm{TiO}_{2}, \mathrm{Au}$ and $\mathrm{CuO}$ that are introduced along with CNF for decomposing the pollutants. High purity of CNFs also improves the crystallinity of the nanofibers. This enhances the compactness of the CNF structure thereby maintaining their integrity. Highly crystalline nature increases the stability of the CNF structure. When combined with other materials having low crystallinity such as PVA, PLA etc., CNF imparts stiffness and high strength to the nanocomposite in addition to the native properties of the added materials. ${ }^{19,20}$ The high crystallinity observed in CNF also enhances their sorption property towards various volatile compounds from water and air. Thus, CNF based adsorbents can be used in the remediation of air and water pollution. Besides this, the sorption ability of CNF can also be utilised in sensors, catalysis and molecular level compound separation applications. CNF can accommodate a wide variety of guest nanoparticles such as $\mathrm{Au}, \mathrm{Ag}, \mathrm{Pb}, \mathrm{Ni}$, $\mathrm{TiO}_{2}, \mathrm{CuO}, \mathrm{SiO}_{2}$ etc. in its structure. This is due to their high mechanical stability, intact crystalline structure, surface area and porosity. An important feature of CNFs is the high concentration of reactive $-\mathrm{OH}$ groups present on their surface that helps in CNF modification. These $\mathrm{OH}$ groups present on the cellulose surface crosslinks with quaternary ammonium compounds forming quaternary amines. This process is called quaternization. Through this process, cationic groups are introduced on the CNF surface to improve the adsorption of anions from polluted water sources. ${ }^{21}$ Apart from being used as ion exchange resins for water purification, the tuneable surface property of CNFs is also exploited in the fabrication of antibacterial water filters, energy devices and sensor applications. For example, CNF-AgNp based water filters prevents biofouling of the membrane and improves the life of the filter used..$^{22}$ The high wettability of CNFs is used in various environmental applications such as water purification, development of absorbents for oil-water separation from oil-spills, anti-fouling coatings etc. The wettability of CNF plays an important role in water and oil separation. While conventional methods have drawbacks of ineffectiveness, high demand of chemicals and energy, CNF based adsorbents (sponges and filters) are effective and efficient alternatives. The CNF adsorbents allow selective permeation of either oil/water and omit the other compound. CNF based environmental friendly anti-fouling coatings has been developed to protect the surfaces of marine vessels, environmental sensors, water treatment plants etc. The CNF coatings due to high wettability prevent the attachment and growth of the microbial flora on the surfaces.

The CNF's can be prepared using physical, chemical, biological and oxidation methods. ${ }^{23}$ In chemical methods, cellulosic nanofibers are prepared through acid digestion, where amorphous area of fibers is destroyed to yield nanocrystalline nanofibers. ${ }^{24}$ During physical methods, the wood pulps are ground at high rpm, subjected to high intensity ultrasonic treatment, mechanical nanofibrillation ${ }^{25}$ to obtain nanofibers of nanometer diameter. ${ }^{26}$ In case of biological treatments, cellulosic materials are treated with cellulolytic enzymes like cellulase that cleave the fiber structures to simpler ones. ${ }^{15,26}$ Since biological treatment takes more time, they are often coupled with mechanical/chemical methods to reduce the process time and get better CNF. ${ }^{23}$ Better yield of CNF has been obtained through oxidation of CNFs mediated through 2,2,6,6tetrame-thylpiperidine-1-oxyl radical. ${ }^{27}$ The exposure of such oxidised fibers to mechanical treatment results in easier defibrillation due to the generation of negative charges that repels the microfibrils against each other inside the cell wall. ${ }^{27}$ The main purpose of the oxidation process is to make the secondary

Table 1 Percentage of cellulose present in various plant sources

\begin{tabular}{lll}
\hline Source & Cellulose content (\%) & Reference
\end{tabular}

Rice husk

Ahu variety

Boro variety

Banana

Eucalyptus

Wheat straw

Rice straw

Flax fibers

Cotton fibers

Corn silage

Hemp fibers

Sisal fibers

Cassava bran

Achirafibers

$\begin{array}{ll}94.2 & 87 \\ 89.6 & 66 \\ 16.62 & 60 \\ 76 & 93 \\ 43 & 89 \\ 71 & 130 \\ 72 & 153 \\ 85-90 & 154 \\ 32 & 155 \\ 68 & 155 \\ 65.5 & 156 \\ 16.71 & 27 \\ 19.1 & 50\end{array}$


Table 2 Shows various sources of CNF, their preparation techniques and their properties

Source of CNF Method of preparation Properties of the material developed

\section{Natural cellulose}

Pineapple peel juice, Gluconacetobacter swingsii sp. Rice husk from Oryza sativa

Fibrous residues of Achira rhizomes

Banana peel

Powder from poplar wood

Poplar wood, culms of moso bamboo, rice straw, corn straw Tomato peels

Posidonia oceanica balls and leaves

Cotton stalks

Waste pulp residues from paper industry

Culinary banana peel

Eucalyptus pulp

Canola straw

Oil palm trunk, oil palm frond, okara

Bacterial cellulose (native)

Acetobacter xylinum

(ATCC10245)

Acetobacter xylinum X-2

Gluconoacetobacter hansenii

(strain NCIM 2529)

Acetobacter xylinum FF-88

Acetobacter xylinum ATCC700178

Acetobacter xylinum

(subspecies-sucrofermentas

BPR2001, Trade number

$\left.700178^{\mathrm{TM}}\right)$

Synthetic cellulose (cellulose acetate)

Commercially obtained Electrospinning Commercially obtained Electrospinning
Spray coating

Hydrothermal approach, acid-alkali treatment, mechanical disruption Acid hydrolysis, high pressure homogenisation

Chemical and enzymatic treatment using xylanase

Chemical pretreatment, high intensity ultrasonication Chemical treatment, ultrasonication, high pressure homogenisation Acidified sodium chlorite, chlorine free alkaline peroxide Chemical treatment, fibrillation

Chemical treatment, ultrasonication, mechanical treatment

Etherification of pulp, mechanical disintegration

Chemical treatment, high intensity ultrasonication

TEMPO mediated oxidation

Nanowelding

Alkaline treatment, electrospinning

Static culture

Static culture

Static culture

Static culture obtained from (Fujicco Co., Ltd.)

Static culture

Static culture
Anti-microbial activity, enhanced spread factor $\left(\xi_{\max }=\right.$ $+0.040 C^{2}$ and $-0.075 C^{2}$ )

Size; $30-40 \mathrm{~nm}$, innate fluorescence property, purity, crystallinity, thermostability

Size; $13.8-37.2 \mathrm{~nm}$, high crystallinity $\left(I_{\mathrm{cr}}=57.5 \%\right.$ and $69.8 \%$ ), biodegradability, mechanical stability

Size; $10.9 \mathrm{~nm}$ and $7.6 \mathrm{~nm}$, biodegradability, high crystallinity $\left(I_{\mathrm{cr}}=49.2 \%\right)$

Size; 5-20 nm, high thermostability $\left(335^{\circ} \mathrm{C}\right)$, high crystallinity $(69.34 \%)$

Size; 2-5 nm, high stability, ribbon like structure, high flexibility

Size; $260 \pm 79 \mathrm{~nm}$, high crystallinity $\left(I_{\mathrm{cr}}=69 \%\right)$

Ref.

Size; 5-21 nm and 2-15 nm

136

87

50

64

61

25

146

Size; 3-15 nm, cost effective, biodegradable

Size; $10-100 \mathrm{~nm}$, high fibrillation, high thermostability $\left(320^{\circ} \mathrm{C}\right)$, high nitrate adsorption capacity $(0.7 \mathrm{mmol}$ $\left.\mathrm{g}^{-1}\right)$

High crystallinity $\left(I_{\mathrm{cr}}=63.64 \%\right)$, high thermal stability $\left(295.33{ }^{\circ} \mathrm{C}\right)$

High water retention value $\left(\mathrm{WRV}=8.3 \mathrm{~g} \mathrm{~g}^{-1}\right)$, high modulus of rupture and modulus of elasticity (MOR = $35 \mathrm{MPa}, \mathrm{MOE}=5160 \mathrm{MPa}$ ), high strength

Size; $53 \pm 16 \mathrm{~nm}$, high tensile strength (208 MPa), Young's modulus $(20 \mathrm{GPa})$, superior transparency (76\%), biodegradability

Size; $<500 \mathrm{~nm}$, high fiber content $(107.9 \%, 67.2 \%$, $25.1 \%)$, high anti-oxidant activity (377.2\%, 367.8\%), superior mineral (Fe, $\mathrm{Zn}, \mathrm{Cu}, \mathrm{Ca})$ binding activity, high emulsion activity $(66.3 \pm 0.6 \%, 6.6 \pm 0.1 \%, 4.0 \pm$ $0.1 \%)$

High cytochrome c adsorption efficiency (36.4 $\mathrm{mg} \mathrm{g}^{-1}$ ), high protein binding efficiency, high selectivity Size; $68 \pm 15 \mathrm{~nm}$ and $117 \pm 15 \mathrm{~nm}$, enhanced cell proliferation, high crystallinity $\left(I_{\mathrm{cr}}=88.3 \%\right)$, excellent hydrophilicity with contact angle $50 \pm 2.4^{\circ}$, favourable thermal stability $\left(290-370{ }^{\circ} \mathrm{C}\right)$, biocompatibility BSA protein adsorption ( $>90 \%$ ), high bioadsorption of $\mathrm{Pb}^{2+}$, enhances porosity and water holding capacity of soil

High flexibility, high transparency (90\%), low coefficient of thermal expansion $\left(4 \mathrm{ppm} \mathrm{K}^{-1}\right)$, low thermal expansion $(0.05 \%)$, high mechanical properties

Cost effective, biocompatibility, promotes migration of fibroblast cells, enhanced deposition of collagen, assist wound closure

Enhanced porosity, high Young's modulus (8.25(1.14) $\mathrm{MPa}$ ), biodegradable, enhanced migration of smooth muscle cells

Size; $10 \mu \mathrm{m}$, biocompatibility 
Table 2 (Contd.)

\begin{tabular}{lll}
\hline Source of CNF & Method of preparation & Properties of the material developed \\
\hline Commercially obtained & Electrospinning & $\begin{array}{l}\text { Size; } 300 \mathrm{~nm} \text { to } 1.5 \mu \mathrm{m} \text {, high specific surface area (4.39 } \\
\left.\mathrm{m} 23 \mathrm{~g}^{-1}\right) \\
\text { Size; } 450 \mathrm{~nm} \text {, enhanced blending capacity with } \\
\text { polymers, enhanced thermostability } \\
\text { Size; } 4.6 \pm 1.8 \mu \mathrm{m} \text { and } 8.1 \pm 2.2 \mu \mathrm{m}, \text { high fluid } \\
\text { permeability }\left(8.9 \times 10^{-12} \mathrm{~m}^{2}\right)\end{array}$ \\
Eommercially obtained & Electrospinning & 151
\end{tabular}

cell wall accessible to mechanical treatment by loosening the primary cell wall. Besides, the water retention value (WRV) of the CNF enhances during the oxidation process and this hydration results in swelling of the fibers thereby making the process of defibrillation easier during mechanical treatment.

Recently cellulose isolated and purified from various agriculture sources have been electrospun to get CNF of various diameters. ${ }^{28}$ However the challenges like solubility of cellulosic biopolymer in conventional solvent system and its properties to aggregate and form gel always leaves processing problems. ${ }^{29}$ Hence researchers have looked into extracellular/intracellular bacterial cellulose as alternative for easing the processing steps. Unlike plant cellulose, bacterial cellulose extraction does not need physical/chemical intervention. Eichhorn et al. reviewed various methods used for the preparation of CNF based nanocomposites. ${ }^{30}$ The authors briefly detailed different methods employed for the extraction of CNF from plants and bacterial sources. In their work, more emphasis was given on CNF based nanocomposites preparation and their applications. ${ }^{30}$ In another study, Chirayil et al. described the preparation of nanocellulose from various fibers of lignocellulosic origin. The review explains in detail various chemical and mechanical treatments employed for the extraction of nanocellulose from plant sources. ${ }^{31}$ Similarly, Wei et al. in 2014 critically reviewed the environmental applications of plants and bacteria derived nanocellulose based nanocomposites. The authors focused mainly on different forms of nanocellulose such as nanofibrillated cellulose, nanocrystalline cellulose etc. ${ }^{32}$ Although there are several reviews available on the CNF extraction from plants and bacterial sources, a consolidated and detailed CNF extraction procedures customised for individual plant and microbial sources, their modification and applications are not available till date. In this study, we have tried to critically review and present consolidated information on CNF extraction from individual plant (cotton, wood pulp, banana, corn and wheat straw, soy hulls and sea grasses) and microbial (bacteria and algae) sources. The review also sheds light on the development of various CNF based composites. The authors also discussed in detail about CNF functionalization using various polymers, nanoparticles and carbon for numerous applications with special emphasis on water purification, biomedical and food packaging. Since the principle behind the methods involved in production of various CNF and its advances has been reviewed already by Nechyporchuk et al. ${ }^{33}$ and the information given in the review has not been included to avoid repeatability.

\section{CNF derived from algal sources}

Algal cellulose was first derived and described in $1885 .{ }^{34}$ In addition to its economic advantage, the extraction of cellulose fibers from various algal sources has been considered as an environmental remediation approach. ${ }^{35}$ The use of algae to extract cellulose fibers helps in preventing the damage caused to the marine ecosystem due to excessive and unwanted blooming of such algae. ${ }^{36,37}$ Cellulose fibers are extracted from green filamentous algae such as Cladophora, Chaetomorpha, Microdyction, Rhizoclonium and members of Siphonocladales. ${ }^{38}$ Pääkkö et al. reported the extraction of cellulose fibers in nanometre size from algal sources using enzymatic hydrolysis and mechanical homogenization. ${ }^{39}$ The cellulose fibers extracted from these algae were reported to have monomers of D-glucose units that are linked by $\beta(1-4)$ linkages similar to the CNFs obtained from wood sources. ${ }^{40}$ Ek et al. reported that the CNF obtained from Cladophora has a radius of $38 \mathrm{~nm}^{41}$ Mihranyan et al. determined the specific surface area of Cladophora CNF to be $95 \mathrm{~m}^{2} \mathrm{~g}^{-1}$ and was reported to have web like structure with multiple intertwined fibers. The individual fiber width was observed to be $25-30 \mathrm{~nm}^{42}$ The season of algal harvesting plays an important role in the strength of the CNF extracted from them. For instance, Mihranyan indicated in his study that the tensile strength of the extracted CNF from algal origin depends on the season they are harvested. Algal harvesting during the early season results in cellulose fibers with low tensile strength due to incomplete development of cell wall. Similar pattern was observed in case of fibers extracted from algae harvested towards the end of the season due to aging. ${ }^{42}$

Johnson et al. reported that midseason exhibits algal cell wall with maximum strength cellulose fibers. CNF with high tensile strength ( $9 \mathrm{Mpa}$ ) has been obtained from Cladophora harvested during the mid of the season. ${ }^{43}$ The CNF extracted from filamentous marine green algae are highly crystalline in nature due to the presence of thick microfibrils of $10-30 \mathrm{~nm}$ width with high degree of orientation. ${ }^{44,45}$ Algal CNFs were reported to have high density $\left(1.64 \mathrm{~g} \mathrm{~cm}^{-3}\right)$ and less moisture absorption due to its high crystallinity. The high crystallinity in algal CNFs provides inertness that is responsible for its resistance to different chemical treatments. ${ }^{46}$ In a study, Hayashi et al. reported that the algal cellulose fibers are rich in I $\alpha$ allomorph that are highly susceptible to enzymatic attack. ${ }^{47}$

CNFs derived from algae have several industrial and environmental significance. They are used as reinforcing agents in polyurethane foams. Such cellulose fiber reinforced materials 


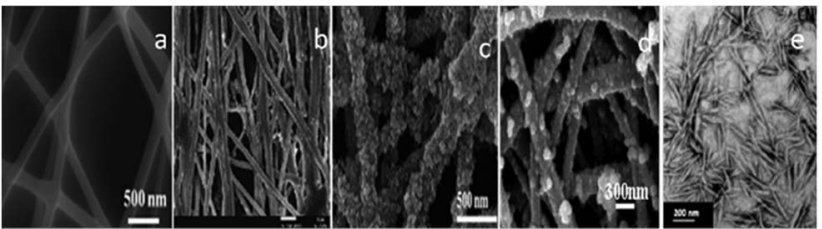

Fig. 1 SEM images of various types of CNF synthesized from cotton (a) natural electrospun $\mathrm{CNF}^{56}$ (b) aligned CNF (scale bar $\left.1 \mu \mathrm{m}\right)^{54}$ (c): CdS functionalized $\mathrm{CNF}^{33}$ (d): $\mathrm{CeO}_{2}$ functionalized $\mathrm{CNF}^{56}$ (e): $\mathrm{CNF}$ prepared by acid hydrolysis ${ }^{52}$ (adopted with permission).

exhibits tremendous improvement in strength, elastic modulus, biodegradability and thermal resistance. Cladophora extracted CNFs also find immense application as filter membrane materials in water purification. They are used in drug delivery purposes due to their inert nature and high surface area. The high drug loading capacity makes them suitable carriers for liquid and solid drug materials. The pores present in the algal CNFs protect the loaded drug molecules from unfavourable environment.

Albert et al. reported that Cladophora CNFs form highly stable and transparent gels by means of high speed sonication. ${ }^{48}$ Their strong rheological properties and robustness makes them suitable materials for food packaging, wound dressings and pharmaceutical applications. Cladophora CNF composites are reported as suitable materials for ion exchange resins and paper based battery fabrication. The insulating property of algal CNF is converted into conductive nature by coating the fibers with polymers such as polypyrrole (PPy) and polyaniline. Such composite algal CNFs are used for the fabrication of conductive paper based energy storage devices. ${ }^{49}$ Such a battery cell consisting of two electrodes, PPy/Cladophora CNF was reported by Nyström $e t$ al. The algal CNF based paper batter systems are cost effective and environmental friendly. ${ }^{49}$

Despite all the advantages, the CNF extraction from algal sources is less compared to plants and bacterial sources. Hence, this review focusses in depth on CNFs derived from plants and bacterial sources in the following sections.

\section{CNF derived from plant sources}

Plant derived CNF (Table 1) has attracted researchers due to their sustainability, availability, low cost and the related characteristics such as large surface to volume ratio, high stiffness, high flexibility, good water resistance, biocompatibility, biodegradability, renewability, low density, enhanced specific strength $^{50}$ and superior thermo-mechanical properties as compared with other commercial fibers. ${ }^{51}$ CNF has been derived from various plant sources like cotton, banana, corn, rice, aloe vera, jute, palm, soya bean, tomato peel, wood pulp and many other agro wastes. Table 1 gives an account of cellulose content present in various plant sources. Since the cellulose content in different agro wastes are varying, the method opted for synthesis of CNF also varies. The CNF from these plant sources have been synthesised using various physical, chemical and biological methods. Physical treatment involves ultra- centrifugation, high speed homogenisation, ultra-sonication etc. whereas chemical treatment involves alkaline exposure, acid hydrolysis and bleaching process. In case of biological treatment process, enzymes such as cellulose and xylanase are used. Best results have been reported in treatments involving combination of these treatments. Table 2 gives detailed information on CNF isolation techniques used for their extraction from various sources, their properties and applications. The following section discusses various methods opted/modified to obtain CNF of desired quality and function.

\subsection{Cotton based CNF}

The cellulose content in natural white cotton (Gossypium hirsutum $\mathrm{L}$ ) is almost close to $100 \%$ and varies from 74 to $90 \%$ in naturally coloured cotton. Such reduced level of cellulose in naturally coloured cotton is attributed towards the presence of more lignin and hemicellulose. ${ }^{52} \mathrm{CNF}$ from cotton have been prepared using various methods like acid hydrolysis, chemical/ ultrasonication process/(2,2,6,6-tetramethylpiperidin-1-yl)oxy radical oxidation (TEMPO) process, electrospinning etc.

The preparation method, source and the surface type of CNF has considerable impact on its thermal degradation properties. ${ }^{17,52}$ CNF prepared from white and coloured cotton by acid hydrolysis had a length of 85-225 $\mathrm{nm}$ and diameter of 6-18 nm. The CNF obtained from white and coloured cotton were 17 to $24 \mathrm{~nm}$ in size and retained its original colour in water even after acid extraction process. They also reported that the coloured CNF were thermally more stable at $180{ }^{\circ} \mathrm{C}$ than white under isothermal oxidizing conditions..$^{52}$

The efficiency of TEMPO mediated oxidation for isolating uniform CNFs from cotton were reported by Soni et $a l .{ }^{17}$ They demonstrated the production of four varieties of CNF from cotton stalks using various chemical approaches. Their method of extraction comprised of fine grinding and sieving of the cotton stalks obtained using 30-80 mesh sieves. The cotton was subjected to $16 \mathrm{~h}$ ethanol treatment for dewaxing followed by drying at $105{ }^{\circ} \mathrm{C}$ for $18 \mathrm{~h}$. The obtained purified cotton stalks were then exposed to acid/alkaline treatment for extracting the cellulose in pure form. First, the cotton stalks were treated with $15 \% \mathrm{NaOH}$ solution for $2 \mathrm{~h}$ at $23{ }^{\circ} \mathrm{C}$. After collecting the resulting fibers, they were washed well using distilled water and subjected to acid hydrolysis by treating with $1 \mathrm{M} \mathrm{HCl}$ solution for $2 \mathrm{~h}$ at $80^{\circ} \mathrm{C}$. After filtering and washing the acid hydrolysed fibers, they were exposed to alkaline treatment again under the conditions mentioned above. Further, the fibers were bleached with sodium chlorite solution at $75{ }^{\circ} \mathrm{C}$ followed by filtration. Soni et al. ${ }^{17}$ demonstrated the extraction of CNFs from the prepared pulp using TEMPO mediated oxidation and acid hydrolysis using $\mathrm{H}_{2} \mathrm{SO}_{4}$. The advantages of including ultrasonication at the end of chemical treatments in the extraction of CNFs were also shown in their study. In acid hydrolysis, the bleached cellulose pulp was treated with $64 \% \mathrm{H}_{2} \mathrm{SO}_{4}$ for $50 \mathrm{~min}$ at $45{ }^{\circ} \mathrm{C}$. To this aqueous solution of $\mathrm{Na}_{2} \mathrm{CO}_{3}$ was added and subjected to centrifugation for $20 \mathrm{~min}$ at $9000 \mathrm{rpm}$. The centrifugation was repeated thrice and the final CNFs obtained were redispersed in water. The TEMPO mediated oxidation 


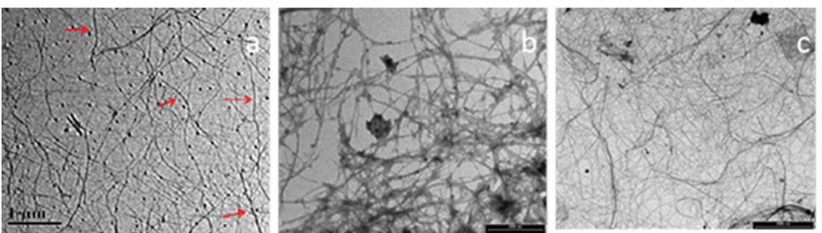

Fig. 2 TEM images of various types of CNF synthesized from banana (a): CNF after high intensity ultra-sonication; ${ }^{60}$ (b) CNF after chemical ${ }^{60}$ and (c) enzymatic treatment ${ }^{64}$ (scale bar: $2 \mu \mathrm{m}$ ) (adopted with permission).

method used for isolating cellulose fibers were similar to the protocol described by Bettaieb et al. ${ }^{53}$ Finally, the acid hydrolysed and TEMPO oxidised cellulose fibers were subjected to ultrasonication in ice water bath for $20 \mathrm{~min} .{ }^{17} \mathrm{The} \mathrm{CNF}$ obtained were of 3 to $50 \mathrm{~nm}$ in size after subjecting to $\mathrm{H}_{2} \mathrm{SO}_{4}$ treatment and TEMPO oxidation process. The thermal degradation temperature was greater with untreated bleached pulp and $\mathrm{H}_{2} \mathrm{SO}_{4}$ neutralised CNF when compared to $\mathrm{H}_{2} \mathrm{SO}_{4}$ dialysed and TEMPO oxidized CNFs. The authors suggested that the CNFs containing free sulfate group in the frame was more thermally stable in the high temperature region than that containing sodium carboxylate group, especially in oxidative conditions. $\mathrm{He}$ et al. ${ }^{54}$ synthesized uniaxially aligned CNF $(212-221 \mathrm{~nm}$ average dia) from cotton based cellulose nano crystals (CNC) using electrospinning process and tested it as scaffold for tissue engineering. For this purpose, a non cellulose degrading solvent system, lithium chloride/dimethyl acetamide (LiCl/DMAc) was used to electrospun non derivative cellulose onto a rotating steel drum collector. $20 \%$ loading of CNC into the cellulose solution increased the tensile strength and elastic modulus of electrospun cellulose/CNCs nanocomposite nanofibers by 101.7 and $171.6 \%$, respectively in the fiber alignment direction. These nanocomposite nanofibers were found to be compatible for hDFCs (human dental follicle cells) attachment and proliferation. Li et al..$^{55}$ prepared electrospun CNF from natural cotton cellulose having degree of polymerization above 10000 . These cotton nanofibers were functionalized and made into composites by coating $\mathrm{CeO}_{2}$ nanoparticles on surface using hydrothermal reaction. This composite nanofiber was reported to possess excellent UV-shielding properties as compared to the natural cotton CNFs that can be used for medical, military, biological, and optoelectronic applications. Similarly, Liu et al. ${ }^{56}$ synthesized CdS nanoparticle-functionalized natural cotton cellulose electrospun nanofibers for photocatalytic applications.

The CNF surfaces were homogeneously dispersed with CdS nanoparticles having cubic zinc-blend structure. These heteromatrices $\mathrm{CNF} / \mathrm{CdS}$ nanocomposite had excellent ability to photo degrade $99 \%$ of Rhodamine B (RhB) under visible light irradiation. The scanning electron microscopic images of various CNF synthesized by above mentioned authors are given in Fig. 1 .

\subsection{Banana based CNF}

The cellulose content present in the banana fibers plays a major role in determining the quality of the fiber. The cellulose content of banana fibers varies from one variety to the other and between one part to the other in the same variety. For example, the peduncle fibre of nendran variety has $60.41 \%$ cellulose whereas grand naine peduncle fibre has only $48.31 \%$ cellulose. Similarly the cellulose content in pseudostem of nendran $(59.22 \%)$ and grand naine $(48.19 \%)$ vary significantly (to know more about the cellulose content of various banana varieties please refer to Preethi and Murthy, 2013). ${ }^{57}$ Hence for attaining good CNF yield, the selection of variety and the part of banana remains crucial. Natural CNF has been prepared from banana peel using high pressure hydrothermal/steam explosion process. During this process, the natural microfibers were alkali treated ( $2 \%$ sodium hydroxide) and subjected to steam explosion process involving pressurized steam (for e.g., pressure of $0.0014 \mathrm{~kg} \mathrm{~cm}^{-2}$ at a temperature of $120^{\circ} \mathrm{C}$ for $1 \mathrm{~h}$ ) and oxalic acid which induces break down of lignocellulosic structure, hemicelluloses hydrolysis, depolymerisation and defibrillation of the lignin components. ${ }^{58} \mathrm{CNF}$ of $\sim 30 \mathrm{~nm}$ dia having increased surface acidity, thermal stability, tensile, flexural, and impact strength which can be used as reinforcement material are obtained using this method. Hooshmand et al..$^{59}$ synthesized filaments containing banana CNF using dry spinning method. Banana rachis was bleached and subjected to ultrafine grinding with a MKZA10 Super Masscolloider which reduced bio residue to a gel. The gel was further dry spun using a capillary rheometer to prepare continuous filaments. The dry spun CNF was collected manually on a glass sheet and dried subsequently. The filaments fracture surface and mechanical properties varied with quantity of CNF present. High-intensity ultrasonication combined with chemical treatment was used to isolate CNF having high thermal stability from culinary banana peel. ${ }^{60}$ The process of high intensity ultrasonication transfers ultrasonic energy to the cellulose chains through cavitation process. ${ }^{61}$ The energy provided by such cavitation process $\left(10-100 \mathrm{~kJ} \mathrm{~mol}^{-1}\right)$ disintegrates the micron size banana cellulose fibers to individual nanosize fibers. ${ }^{62}$ However increasing the ultrasonic energy beyond has considerable impact on nanofibrillation. Pelissari et al. ${ }^{63}$ isolated CNF from banana peel using combination of alkaline treatment, bleaching, and acid hydrolysis followed by subjecting the pre-treated banana peel to high pressure homogenisation several times. The reduced particle size of CNF with increased zeta potential and stability in suspension was achieved with increase in homogenization cycle. Tibolla et al. ${ }^{64}$ combined chemical and enzymatic treatment to isolate CNF from Musa paradisiaca (Terra) variety of plantin bananas (unriped) peel. Banana peel was subjected to alkaline treatment, bleaching, and acid hydrolysis in combination along with xylanase enzyme. In brief, the peel of the bananas were removed and soaked in $1 \%$ potassium metabisulphite solution for one day and was dried in oven at $60{ }^{\circ} \mathrm{C}$ for one day. The dried banana material was then milled and dried in oven at $60^{\circ} \mathrm{C}$ for $24 \mathrm{~h}$ after ethanol wash. The content was sieved using 200 mesh sieve and prepared for further subjected to chemical as well as enzymatic treatments. In chemical treatment, the bran was first stirred with $5 \% \mathrm{KOH}$ solution at room temperature (RT) for $14 \mathrm{~h}$ and then subjected to delignification by bleaching using $1 \% \mathrm{NaClO}_{2}$ for $1 \mathrm{~h}$ at $70{ }^{\circ} \mathrm{C}$. 
This was further subjected to second $\mathrm{KOH}$ treatment at RT for $14 \mathrm{~h}$. The residue obtained at the end of second alkaline treatment was then exposed to acid hydrolysis using $1 \% \mathrm{H}_{2} \mathrm{SO}_{4}$ solution for $1 \mathrm{~h}$ at $80{ }^{\circ} \mathrm{C}$. The residues obtained at the end of each step of the acid-alkali treatment were centrifuged at $10000 \mathrm{rpm}$ for $20 \mathrm{~min}$ at $5{ }^{\circ} \mathrm{C}$. The final $\mathrm{CNF}$ residues achieved was washed well with water and stored at $4{ }^{\circ} \mathrm{C}$. In the enzymatic treatment, the prepared bran was pre-treated with acetate buffer and subsequently subjected to xylanase treatment for $24 \mathrm{~h}$ at $45{ }^{\circ} \mathrm{C}$ under constant stirring. Further, this solution was immersed in a water bath at $80^{\circ} \mathrm{C}$ for $30 \mathrm{~min}$. The resulting pulp was centrifuged at $10000 \mathrm{rpm}$ at $5{ }^{\circ} \mathrm{C}$ for $15 \mathrm{~min}$ after thorough water wash to obtain colloidal suspension of CNFs. ${ }^{64}$ The resulted CNFs had diameters of 10.9 and $7.6 \mathrm{~nm}$, when treated with chemical and enzymatic process respectively. The CNF obtained by enzymatic treatment showed stable suspension with higher zeta potential and aspect ratio when compared chemically treated banana peel. Likewise, Khawas and Deka ${ }^{60}$ demonstrated the isolation of CNFs from banana peel by combining chemical and mechanical approach of extraction. The fresh culinary bananas (musa ABB variety) was collected and washed well using water and further soaked in $1 \%$ potassium metabisulphite solution for $12 \mathrm{~h}$ after separating their pulp. The peels were then subjected to tray drying for a day at $50{ }^{\circ} \mathrm{C}$ followed by grinding and sieving using $0.25 \mathrm{~mm}$ mesh sieve. The peel flour was first subjected to alkaline treatment for $1.5 \mathrm{~h}$ at $170{ }^{\circ} \mathrm{C}$ by exposing them to $20 \% \mathrm{NaOH}$ and $0.1 \%$ anthraquinone. Followed by distilled water wash, they were further subjected to bleaching using $1 \%$ sodium chlorite for $1 \mathrm{~h}$ at $70{ }^{\circ} \mathrm{C}$. This step was repeated once again under the same conditions to obtain efficiently decoloured fiber material. After thorough bleaching, the material was treated with $5 \%$ solution of $\mathrm{KOH}$ at $25{ }^{\circ} \mathrm{C}$ for $15 \mathrm{~h}$ followed by centrifugation at $10000 \mathrm{rpm}$ for $20 \mathrm{~min}$ at $4{ }^{\circ} \mathrm{C}$. The pellet obtained was redispersed in water and subjected to acid hydrolysis using $1 \%$ sulphuric acid solution for $1 \mathrm{~h}$ at $80{ }^{\circ} \mathrm{C}$ and centrifuged under similar conditions as briefed above. The pellet generated was redispersed in deionised water and then subjected to high intensity ultrasonication at $400 \mathrm{~W}, 800 \mathrm{~W}$ and $1000 \mathrm{~W}$ for $30 \mathrm{~min}$ in ice water bath. The obtained purified CNFs were freeze dried and stored at $4{ }^{\circ} \mathrm{C} .{ }^{60}$ Various structures of banana based CNF are given in Fig. 2 .

\subsection{Wood pulp based CNF}

Wood based CNF are advantageous over other plant based CNFs due to its high cellulose purity, strong and ductile networks formed via CNF-CNF bonding of fibrils, ${ }^{65}$ high intrinsic physical properties, ${ }^{6}$ zero axial thermal expansion, ${ }^{67}$ and high biodegradability. ${ }^{68}$ CNFs have been isolated from both soft and hard wood pulps. The structure of hardwoods is more complex and heterogeneous than softwoods. Hardwood have specialized vessel elements involved in transport functions and shorter fiber cells when compared to softwood. ${ }^{69}$ Due to the complex nature of the wood pulp, scientists have mostly used mechanical process for isolation of CNF from hard and softwood pulps. Stelte and Sanadi ${ }^{70}$ isolated CNF from commercial hardwood and softwood powders through mechanical fibrillation process by subjecting the wood pulps to initial refining followed by high-pressure homogenization. Isolation of CNF from hardwood pulps are difficult than softwood pulps and can affect the CNF isolation process through pressure fluctuations and clogging of the homogenizer. The number of passes used for homogenization process was kept high in hardwood pulp when compared to softwood pulp. The number of passes in hard wood pulp can be reduced by using appropriate sieves. Abe et $a .^{71}$ isolated CNF from radiata pine wood powder using simple mechanical process. The wood pulps subjected to grinding treatment in an undried state yielded CNF having uniform width of approximately $15 \mathrm{~nm}$. Ultrafine polysaccharide nanofibers $(5-10 \mathrm{~nm})$ were prepared by treating microcrystalline $\alpha$-cellulose obtained from wood pulp (Biofloc $92 \mathrm{MV}$ ) with TEMPO/NaBr/NaClO method. ${ }^{72}$ These nanofibers were used to synthesis thin-film nanofibrous composite (TFNC) membranes useful for water purification. Yano et al. ${ }^{73}$ successfully isolated CNF from soft wood (kraft pulp) and made composite films having high optical transparency using it as reinforcements in acrylic resins. The kraft pulp was bead milled followed by acetylation to reduce the hydrogen bond found between the natural CNF in pulp. Such acetylation process with decreased moisture content showed increased hydrophobicity. Terenzi et al. ${ }^{74}$ used a combination of process to obtain CNF from softwood sulphite pulp. The softwood pulp was subjected to enzymatic degradation, mechanical beating and disintegration by passing through microfluidizer to obtain CNF of $6.6 \mathrm{~nm}$ diameter and more than $700 \mathrm{~nm}$ length. Galland et $a l^{75}$ prepared hollo CNF of high molar mass and small diameter that can be used for preparing high strength nanopapers. Aspen wood chips were chemically treated using chelating agents like diethylene triaminepentaacetic acid (DTPA)/sodium sulfite solution to remove metal ions. ${ }^{76}$ Such treatment increase peracetic acid bleaching and cellulose stability. ${ }^{77,78}$ Further the pulp was subjected to alkali treatment and mechanical disintegration using microfluidizer. The process yielded unique core shell CNF nanofibers having $0.2 \mathrm{~nm}$ "shell" made of hemicellulose (up to $24 \%$ ) and $3.6 \mathrm{~nm}$ "core" CNFs. These CNF also had appreciable optical transparency and mechanical strength that can contribute to the strength of the CNF based nanopapers. Chen et $a .^{61}$ separated and individualized CNF (5-20 nm dia) from delignified hemicelluloses free poplar wood using combined chemical and high-intensity ultrasonication process $(1000 \mathrm{~W})$. The degradation temperature of these CNF increased from $210{ }^{\circ} \mathrm{C}$ to $335{ }^{\circ} \mathrm{C}$ when compared to that of original wood fibers. Needle-leaf bleached kraft pulp was mechanically disintegrated using a bead mill to get CNF.11 The obtained CNF was further surface modified using alkenyl succinic anhydride for its efficient use as reinforcement matrix in high-density polyethylene. Zhao et $a l^{79}$ used high shear homogenisation process to extract CNF from dry softwood pulp. The extracted CNF were having a diameter ranging from 16-28 nm; however the thermal stability was low. Never-dried wood pulp was enzymatically treated using commercial enzyme (Novozym ${ }^{\circledR} 476$ ) followed by subjecting to high shear forces through microfluidizer to obtain CNF of $0.8-2.0 \mu \mathrm{m}$ 
length and $10 \mathrm{~nm}$ dia. ${ }^{80}$ Similar treatments combining enzyme and microfluidizer were carried out to extract CNF from neverdried spruce sulfite pulp. ${ }^{59}$ The size of these nanofibers ranged from 2.5 to $10.5 \mathrm{~nm}$.

\subsection{Rice based CNF}

Different parts of rice (Oryza sativa sp.) namely straw, stalk, husk etc. are an abundant source of CNF. The predominant component present in the cell wall of rice straw is cellulose. The cellulose chains are hydrogen bonded with each other resulting in formation of cellulose microfibrils with high tensile strength and crystallinity. Such cellulose microfibrils are further bonded with a gel matrix composed of hemi cellulose, lignin and other carbohydrates. This high crystallinity of the cellulose and the complex lignin and hemicellulose structure makes extraction of CNFs difficult from rice straw. ${ }^{81-83}$ Different techniques have been employed for isolation of CNF from rice. Although there are several physical treatments available for extraction of cellulose from rice based plant materials like crushing and grinding, steam explosion has been reported to be effective for preparing the rice straw for chemical and enzymatic interaction. ${ }^{84}$ Among various methods reported, steam explosion (hydrothermal treatment) in combination with acid-alkaline exposure has been reported to be efficient method for CNF production since the extracted CNF has high thermal stability $\left(280{ }^{\circ} \mathrm{C}\right)$, excellent crystallinity, mechanical stability and remarkable purity. The exposure of rice straw to steam explosion leads to the breakdown of biopolymer and results in defibrillation of cellulose. ${ }^{\mathbf{8 5}, 86}$ These highly stable CNF's have been considered as potential reinforcing material for composite preparation. Such CNFs have wide applications as drug delivery vehicles, reinforcing agents, soft tissue replacements and food packaging material. ${ }^{5,86}$ The husk of the rice is also a potential source of CNF. Besides their thermal stability and crystallinity, the CNFs extracted from rice husk exhibited outstanding fluorescence emission capacity with remarkable quantum yield. Compared to other plant sources of CNFs, the intrinsic fluorescence ability is unique to rice husk. ${ }^{87}$ The extracted CNF exhibited blue fluorescence when illuminated under UV light. The mechanical treatment and acid hydrolysis of rice husk led to the generation of CNF with trace amounts of lignin content having syringyl group and phenylcoumarone group which are responsible for its fluorescence property. Kalita et al. ${ }^{87}$ reported the production of highly fluorescent CNFs from two rice varieties (Oryza sativa L. ssp. indica) namely Ahu and Boro. They followed hydrothermal treatment, acid-alkali exposure and mechanical disintegration to achieve CNFs of $35 \mathrm{~nm}$. After washing and drying, the risk husk was made into fine particles by milling. The material was pre-treatment by soaking it with $2 \%$ $\mathrm{NaOH}$ for $14 \mathrm{~h}$ followed by autoclaving at $210 \pm 5{ }^{\circ} \mathrm{C}$ and $20 \mathrm{lb}$ pressure for $8 \mathrm{~h}$ with subsequent washing to remove the $\mathrm{NaOH}$. In order to bleach the autoclaved fibers, the material was exposed to a mixture of $\mathrm{NaOH}$-acetic acid and sodium hypochlorite solution. The bleaching of the fibers was followed by distilled water washing and drying. Further, the fibers were exposed to acid treatment by sonicating them in $10 \%$ solution of $\mathrm{HCl}$ at

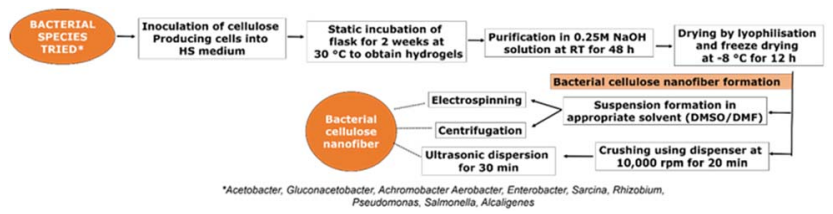

Fig. 3 Various steps involved in the extraction of bacterial CNFs.

$40{ }^{\circ} \mathrm{C}$ for $2 \mathrm{~h}$. This was followed by multiple steps of thorough washing and drying to obtain highly homogenous and fluorescent CNFs. ${ }^{87}$ Similarly, Nasrabadi et al. ${ }^{88}$ reported the extraction of CNF from rice straw using a chemo-mechanical method. The extracted CNF had a diameter of 70-90 $\mathrm{nm}$ with high crystallinity. The extraction protocol included alkali pre-treatment of the rice straw using $\mathrm{NaOH}(17.5 \mathrm{wt} \%)$ for $2 \mathrm{~h}$ followed by acid hydrolysis using diluted $\mathrm{HCl}$ at $80 \pm 5{ }^{\circ} \mathrm{C}$ up to $3 \mathrm{~h}$. The acid treated fibers were further subjected to alkali treatment ( $2 \mathrm{wt} \% \mathrm{NaOH}$ at $80 \pm$ $5{ }^{\circ} \mathrm{C}, 2 \mathrm{~h}$ ) and air dried. After bleaching the treated fibers using sodium chlorite solution for $1 \mathrm{~h}$, they were defibrillated by sonication $(20 \mathrm{KHz})$ for $30 \mathrm{~min}$ in ice water bath. Chen et al. ${ }^{\mathbf{1}}$ demonstrated the extraction of CNF by hydrothermal treatment which included grinding and exposure to steam at $160^{\circ} \mathrm{C}$ at 2 bar. Finally, the filtered and washed fiber residues were oven dried at $60{ }^{\circ} \mathrm{C}$ for $16 \mathrm{~h}$ to yield $\mathrm{CNF}$.

\subsection{Other sources of CNF}

In addition to the above mentioned sources, CNF have been extracted from other agro and plant based sources like corn straw, ${ }^{\mathbf{1 8 0}}$ wheat straw, soy hulls, rhizomes, seagrass etc. Alemdar and Sain $^{89}$ reported the isolation of CNF from wheat straw and soy hulls using chemical-mechanical treatments. The CNF isolated from wheat straw had a diameter of 10-80 $\mathrm{nm}$ while soy hull based CNF had a diameter of 20-120 nm. This approach enhanced the cellulose extraction to $84 \%$. The extracted CNF exhibited remarkable thermal stability $\left(290{ }^{\circ} \mathrm{C}\right)$ and crystallinity. The extraction protocol briefly consisted of alkali treatment of the raw materials ( $\mathrm{NaOH} 17.5 \% \mathrm{w} / \mathrm{w}$ for $2 \mathrm{~h}$ ) followed by acid hydrolysis for $2 \mathrm{~h}\left(1 \mathrm{M} \mathrm{HCl}\right.$ at $\left.80 \pm 5{ }^{\circ} \mathrm{C}\right)$. The treated material was once again subjected to similar alkali treatment and was filtered using vaccum before drying at RT. The dried fibers were then exposed to cryocrushing, defibrillation (2000 $\mathrm{rpm}$ ) and high pressure homogenisation (>300 bar). ${ }^{89}$ Lignocellulosic materials such as achira rhizomes also serves as an excellent source of CNF due to their specific properties and high cellulose content present in them. The isolated CNF are commonly used as fillers for films with high biodegradability. ${ }^{\mathbf{5 0}}$ Andrade-Mahecha et $a .^{50}$ demonstrated the development of various methods for the extraction of CNFs from the starch extract fibrous material of achira rhizomes. They introduced modifications in the bleaching process, acid hydrolysis and mechanical treatment steps to achieve high quality nanofibers. The achira rhizomes were dried, ground and sieved followed by alkaline treatment using $5 \% \mathrm{KOH}$ for $13 \mathrm{~h}$ at RT. The content was chelated using $0.025 \%$ EDTA for $1 \mathrm{~h}$ at $70{ }^{\circ} \mathrm{C}$ and exposed to a couple of bleaching processes. The bleached materials were 
subjected to second $\mathrm{KOH}$ treatment for $13 \mathrm{~h}$ at RT. Well dispersed CNF suspension was obtained after acid hydrolysis (1\% $\mathrm{HCl}$ at $80{ }^{\circ} \mathrm{C}$ for $\left.1-2 \mathrm{~h}\right)$ and high pressure homogenisation. ${ }^{50}$ The CNF extracted were in the size range of 13.8-37.2 nm with high crystallinity (69.8\%). They also had high negative surface charge which is an important factor in deciding the stable dispersion of CNF in suspension. ${ }^{90}$ Effective isolation of $\mathrm{CNF}$ has been reported from sea grasses that can be utilised for the development of various bionanocomposites. The isolation of CNF from Posidonia oceanica leaves and balls have been reported using simple TEMPO mediated oxidation method followed by mechanical disintegration. Compared to other chemical treatments, TEMPO mediated oxidation is reported to have higher CNF yield (>90\%). ${ }^{91}$ They attempted to demonstrate the relation between concentration of the oxidant used and different grades of CNFs obtained based on it. In addition, they also combined the advantages of mechanical treatment, ultrafine grinding along with TEMPO oxidation to achieve highly disintegrated CNFs. Briefly, the raw materials were dissolved in sodium bromide and TEMPO containing distilled water and the reaction was initiated by the introduction of $\mathrm{NaClO}$ into the suspension under constant stirring at RT. $\mathrm{pH}$ was maintained at 10.0 using $\mathrm{NaOH}$. Ethanol was added to the suspension finally and the cellulose fibers produced were filtered and washed multiple times using distilled water. The obtained fibers were nanofibrillated after dispersing it in water using a high intensity ultrafine grinder at $2500 \mathrm{rpm} .^{91}$

Chen et $a .^{25}$ demonstrated efficient CNF extraction from different sources such as newspaper, corn straw, bamboo, wood and rice straw using three different mechanical nanofibrillation techniques namely, blender, ultrasonicator and high pressure homogenizer. All raw materials were collected, sieved and airdried. The materials were dewaxed for $6 \mathrm{~h}$ in mixture of benzene : ethanol solution $(2: 1)$. Later, the samples were acidified multiple times for $1 \mathrm{~h}$ at $75{ }^{\circ} \mathrm{C}$ using sodium chlorite solution and subsequently treated with $3 \% \mathrm{KOH}$ for $1 \mathrm{~h}$ at $90{ }^{\circ} \mathrm{C}$. Another cycle of acidification and alkaline treatment using $\mathrm{KOH}$ was carried out under the same conditions as mentioned above to produce highly purified cellulose pulp. For nanofibrillation of cellulose pulp using a blender, the pulp was made into suspension using distilled water and agitated for $20 \mathrm{~min}$ using a domestic blender. In case of ultra-sonication, the cellulose suspension was subjected to high intensity ultra-sonication for $20 \mathrm{~min}$ at $1200 \mathrm{~W}$. Similarly, during high pressure homogenisation, the purified cellulose suspension was first fibrillated using high intensity ultrasonicator for $5 \mathrm{~min}$ at $1000 \mathrm{~W}$. These samples were then exposed to high pressure homogeniser for $20 \mathrm{~min}^{25}$ The benefits of adopting a combination of chemical and mechanical treatment for the extraction of CNFs were reported by Sehaqui et al. ${ }^{92}$ In their study, cationic CNFs were isolated from pulp residues. The pulp material was beaten mechanically and allowed to react with aqueous $\mathrm{NaOH}$ to result in suspension. Under constant stirring, glycidyltrimethyl ammonium chloride was introduced to the suspension at $65{ }^{\circ} \mathrm{C}$ and the reaction was allowed to proceed for $8 \mathrm{~h}$. It was then treated with $\mathrm{HCl}$ followed by filtration and washing. Finally, the resulting material was dispersed in water and agitated well for
$10 \mathrm{~min}$. This was later taken for high shear homogenisation for the disintegration of cellulose fibers at 1200 bar pressure. ${ }^{92}$ Similarly, Theng et al. ${ }^{93}$ demonstrated the production of CNFs from Eucalyptus pulp and corn biomass using TEMPO mediated oxidation. The corn pulp production comprised of chopping the corn biomass and sieving those using $10 \mathrm{~mm}$ mesh sieve. They were then boiled in a digester for $15 \mathrm{~min}$ at $160{ }^{\circ} \mathrm{C}$ using distilled water in ratio of $6: 1$. The obtained pulp was washed well and filtered using a Sprout-Waldron refiner. The resulting pulp material was vaccum dried and stored at RT. The TEMPO oxidation carried out were similar to the protocol followed by Soni et $a{ }^{17}{ }^{17}$ After TEMPO mediated oxidation, the resulting fibers were exposed to mechanical disintegration using high pressure homogeniser operating at 600 bar pressure for $5 \mathrm{~min}$ at $60-70{ }^{\circ} \mathrm{C}$. This resulted in the formation of CNF gels. ${ }^{93}$

\section{CNF derived from bacterial sources}

\subsection{Natural bacterial CNF synthesis}

CNFs are produced by various bacterial species. Gram positive bacteria belonging to species such as Gluconacetobacter hansenii and Gram negative species such as Agrobacterium, Achromobacter, Aerobacter, Enterobacter, Sarcina, Rhizobium, Pseudomonas, Salmonella and Alcaligenes spare well known in this category. Lee et $a{ }^{.94}$ has reviewed in detail the metabolic and genetic pathway involved in the production of bacterial CNFs. The review also shed light on various bioreactor systems being employed for the production of CNFs using bacteria. ${ }^{94}$ Different forms of bacterial CNF structures such as spheres, gels, sheets, membranes, mats etc. can be produced by introducing simple modifications in the production strategy. Detailed descriptions of various steps involved in the synthesis of bacterial CNFs are given in Fig. 3.

Mohite et $a l .{ }^{95}$ reported the synthesis of bacterial cellulose from Gluconacetobacter hansenii NCIM 2529 using shaking culture method for various environmental applications. The organism was maintained in a medium containing yeast extract, mannitol, peptone and agar at a $\mathrm{pH}$ 5.5. For the production of cellulose, the organism was cultured in Hestrin and Schramn (HS) medium which was composed of citric acid monohydrate, glucose, peptone, yeast extract and $\mathrm{Na}_{2} \mathrm{HPO}_{4} \cdot 12 \mathrm{H}_{2} \mathrm{O}$ at pH 5.0. Their production protocol involved inoculation of the organism in the HS medium and culturing them for $120 \mathrm{~h}$ at $30^{\circ} \mathrm{C}$ at a speed of $120 \mathrm{rpm}$. After incubation, bacterial cellulose containing broth was obtained and filtered, resulting in bacterial cellulose beads which were further purified using $0.1 \mathrm{~N} \mathrm{NaOH}$ for $30 \mathrm{~min}$ at $90{ }^{\circ} \mathrm{C}$. This is followed by filtration and thorough washing using distilled water. The resulting cellulose was finally dried in the oven for $8 \mathrm{~h}$ at $50{ }^{\circ} \mathrm{C}$. The obtained CNF was reported to be white, translucent and oval shaped spheres containing micro and nano sized fine fibers. The resulting fibers exhibited high elasticity, surface area, wettability and strength. ${ }^{95}$ Similar method was adopted by Fang et al. ${ }^{96}$ for the production of CNFs using G. xylinus that were genetically modified using Agrobacterium sp. ATCC31749. The genetically transformed organism was cultured in HS medium at $30{ }^{\circ} \mathrm{C}$ for 2.5 days with $0.1 \%$ additional cellulose. The bacterial cells 


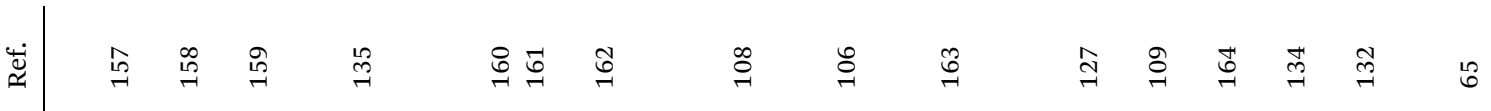

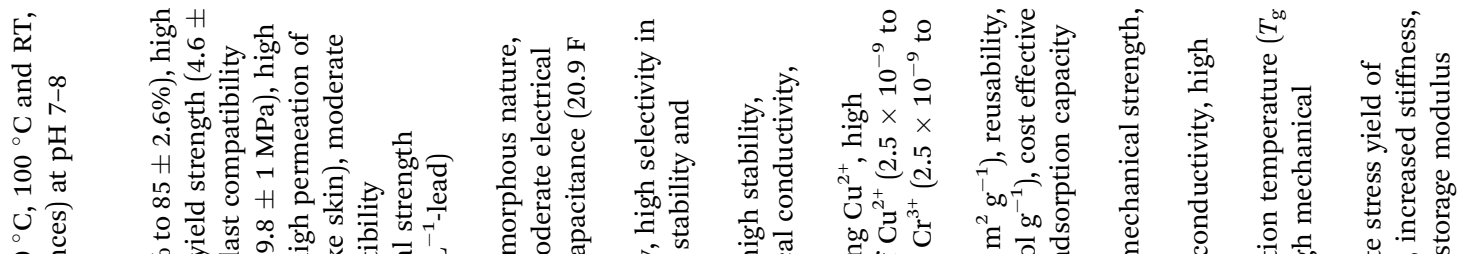

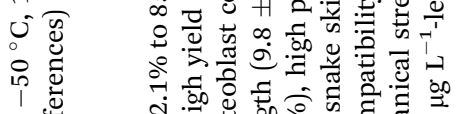

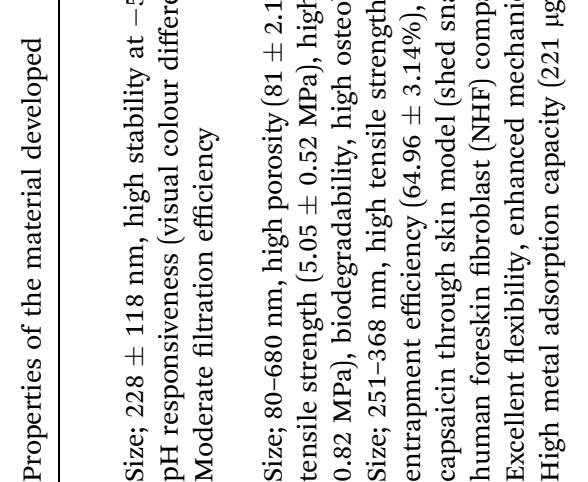

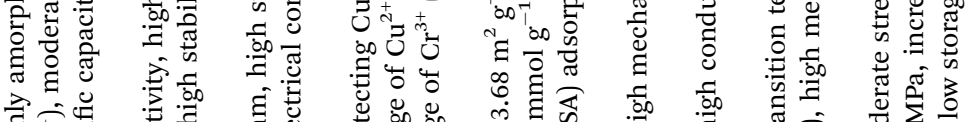

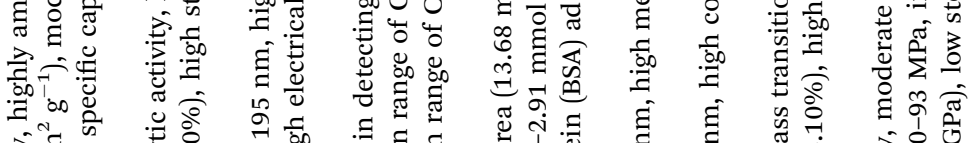
की

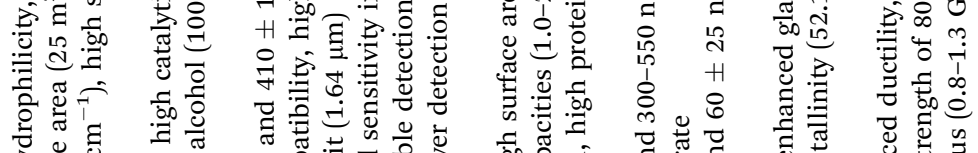

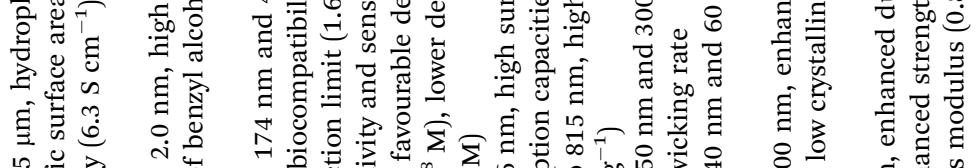

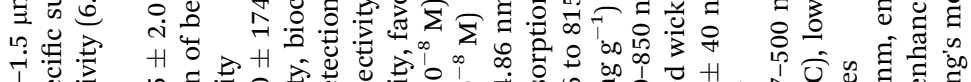
1.

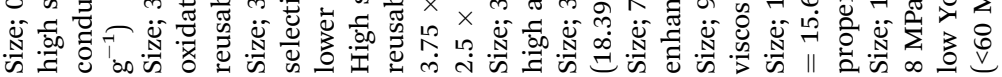

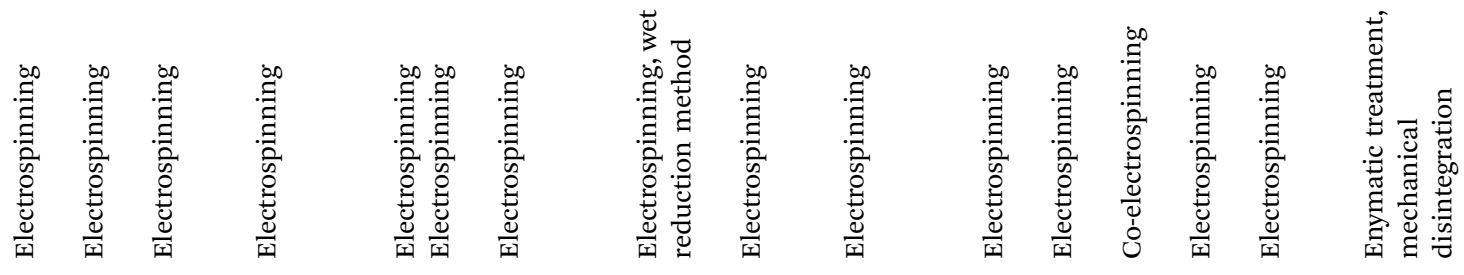

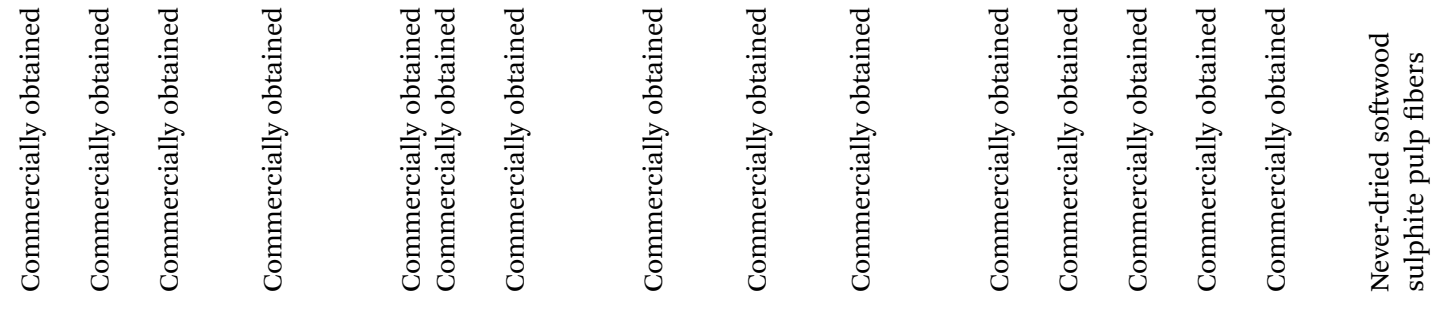




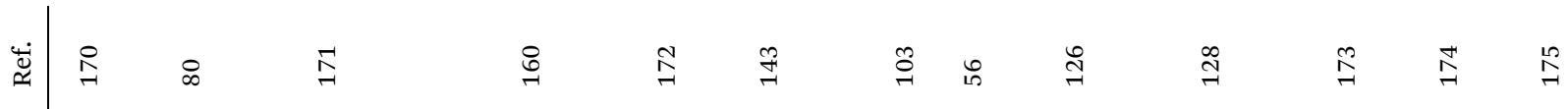
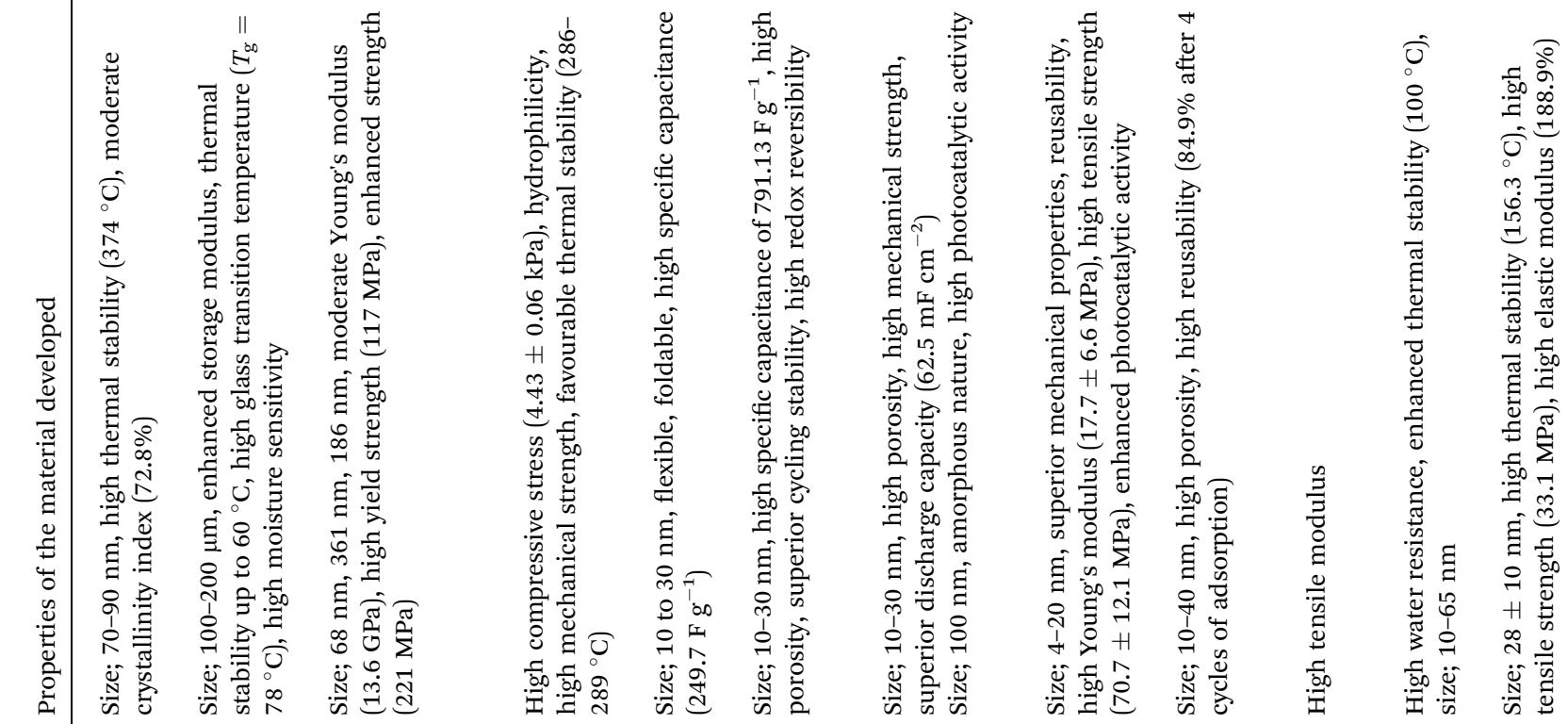

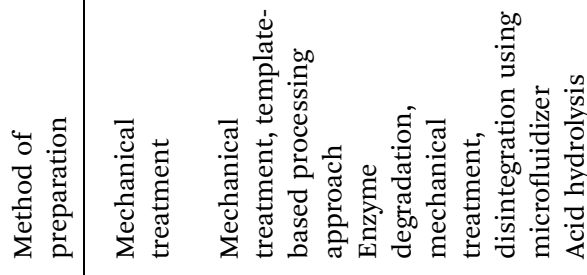

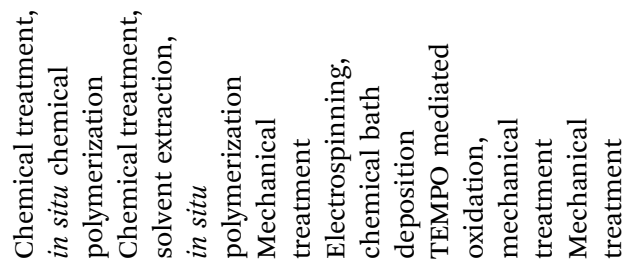

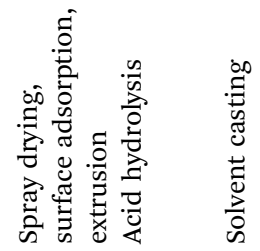
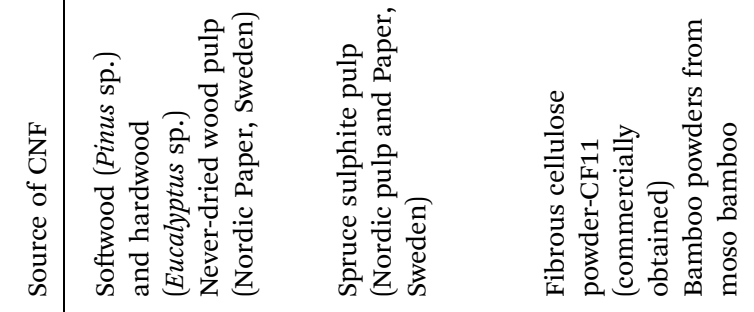

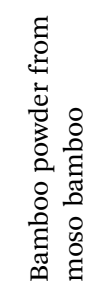
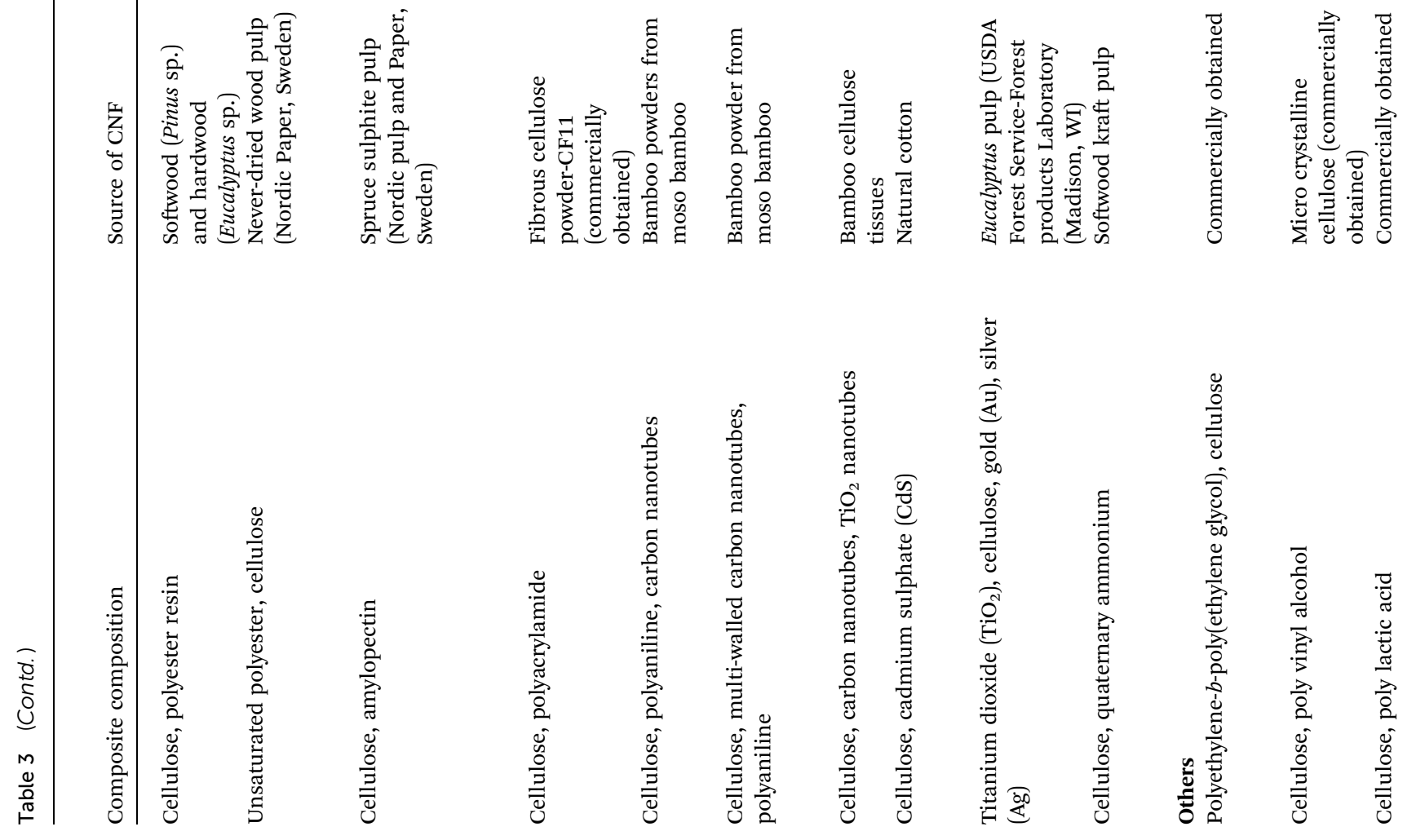


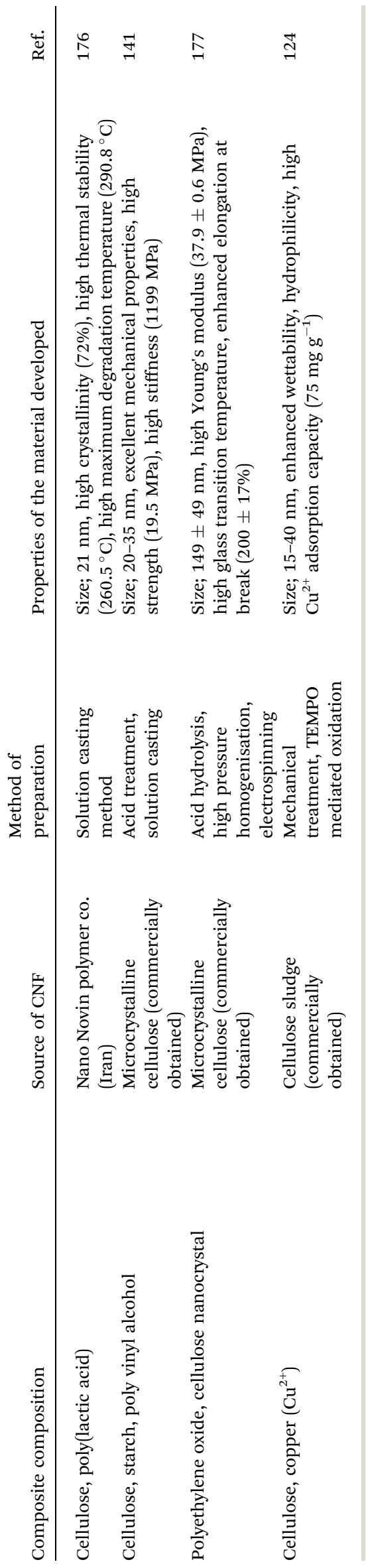

obtained by high speed centrifugation was washed thoroughly using concentrated glycerol and was further maintained at $80{ }^{\circ} \mathrm{C}$. This method produced CNFs that were highly crystalline in nature. ${ }^{96}$ Gonçalves et $a .^{97}$ reported the production of bacterial CNF using static culture technique. In this work, bacterial CNF were produced from G. xylinus ATCC 53582. The organism was cultured for 30 days in HS medium. The bacterial cellulose sheets produced were purified using $0.1 \mathrm{~N} \mathrm{NaOH}$. After thorough washing using distilled water, the cellulose sheets were cut in to appropriate sizes and dried at $50{ }^{\circ} \mathrm{C}$ for $8 \mathrm{~h}$. Biocompatible, highly porous, ultrafine CNFs were produced using this technique. ${ }^{98}$ Similarly, Quero et al. ${ }^{98}$ reported the production of bacterial CNF gel using static culture. In their study, G. xylinum 13693 was cultured in the HS medium for 14 days at $27^{\circ} \mathrm{C}$ during which highly fibrous cellulose gel was formed. The gel was then squeezed in sterile environment to produce suspension of cells. To the main culture medium, the prepared cell suspension was inoculated and maintained for 14 days. The formed bacterial cellulose fibrous structure was then purified using $\mathrm{NaOH}$ and distilled water. In order to remove the water content completely from the produced cellulose network, their group adopted the method of hot pressing at $120{ }^{\circ} \mathrm{C}$ for 4 min..$^{98}$ Apart from cellulose gels, mats of bacterial CNFs were also produced using static culturing technique. For instance, Olsson et al. ${ }^{99}$ developed a protocol for the synthesis of bacterial cellulose mats containing microfibers and nanofibers using G. xylinus (ATCC 23767). The procedure comprised of initial inoculation of the bacteria in $2 \mathrm{~mL}$ culture medium to produce initial suspension containing cellulose. After 3 days, the cellulose suspension obtained was used as the inoculum for second cycle of culturing in higher volume of growth medium. This cycle was repeated with higher volumes of culture medium until final inoculation in $20 \mathrm{~L}$ of medium. Pure cellulose mat generation was observed after 2 days of final inoculation in the medium while a fully grown cellulose mat was harvested by the 7th day. The obtained mats were further purified by boiling in $\mathrm{NaOH}$ solution and washing with distilled water. The water content was completely removed by compressing the mats into thin sheets after which it was stirred continuously at $60{ }^{\circ} \mathrm{C}$ for $72 \mathrm{~h}$ in aqueous $\mathrm{H}_{2} \mathrm{SO}_{4}$. This step completely dissolved the cellulose in the solution. To obtain CNF suspension, the acid dissolved cellulose suspension was subjected to 3 cycles of centrifugation under isothermal conditions at $24000 \mathrm{rpm}$. The final cellulose pellet obtained was redispersed in distilled water or appropriate solvent using high shear mixer for 5 min..$^{99}$

In another study, Lee et al. ${ }^{\mathbf{1 0 0}}$ reported the extraction of bacterial CNFs from coconut gel using Acetobacter sp. The synthesis protocol comprised thorough blending of the gel contents using a high speed blender after they were washed carefully using deionised water. The contents were then subjected to high speed homogenisation at $20000 \mathrm{rpm}$ followed by centrifugation at $14000 \mathrm{~g}$. The purification of bacterial CNFs were then carried out by boiling the water dispersed cellulose content in $\mathrm{NaOH}$ for 20 min. A final centrifugation step was carried out to obtain highly homogenous bacterial CNFs. This procedure resulted in the formation of nanofibers of $50 \mathrm{~nm}$ size. ${ }^{\mathbf{1 0 0}}$ Acetobacter xylinum derived bacterial CNF hydrogel was 
produced by Bäckdahl et al. ${ }^{\mathbf{1 0 1}}$ for the synthesis of highly porous tissue engineering scaffold. In his work, sub species of $A$. $x y l i$ num sucrofermentas BPR2001 was used as the source of CNF. Corn steep liquid media was used as both culture and production medium.

\section{CNF composites}

CNF obtained from both plant and bacterial sources has been combined with various metals and non-metals such as carbon, nanoparticles, fluorophore, polymers etc. to prepare composites for numerous applications (Table 3). The high mechanical strength and integrity of the CNF provide remarkable properties to the composites. Such composites find immense applications in water purification, food packaging, supercapacitor preparation, tissue engineering etc. A detailed view on various CNF based nanocomposites has been given in Table 2. Association of CNF with carbon nanotubes are well known for their application as supercapacitor electrodes. $\mathrm{CNF} /$ carbon nanotubes were blended with polyaniline (PANI), ${ }^{102} \mathrm{TiO}_{2}$ nanotubes ${ }^{\mathbf{1 0 3}}$ and nitrogen ${ }^{\mathbf{1 0 4}}$ for achieving high mechanical strength, flexibility, excellent cyclability, high discharge capacity and remarkable specific resistance. Besides flexible electronics, they were also used in wearable textiles. ${ }^{\mathbf{1 0 3}} \mathrm{CNF}$ for such applications were obtained from plant sources such as bamboo tissues using mechanical grinding at $1500 \mathrm{rpm}$ (ref. 82) and from bacterial cellulose. ${ }^{104}$ Fig. 4 and 5 shows SEM images of composite CNF obtained using bacterial CNF and plant based CNF.

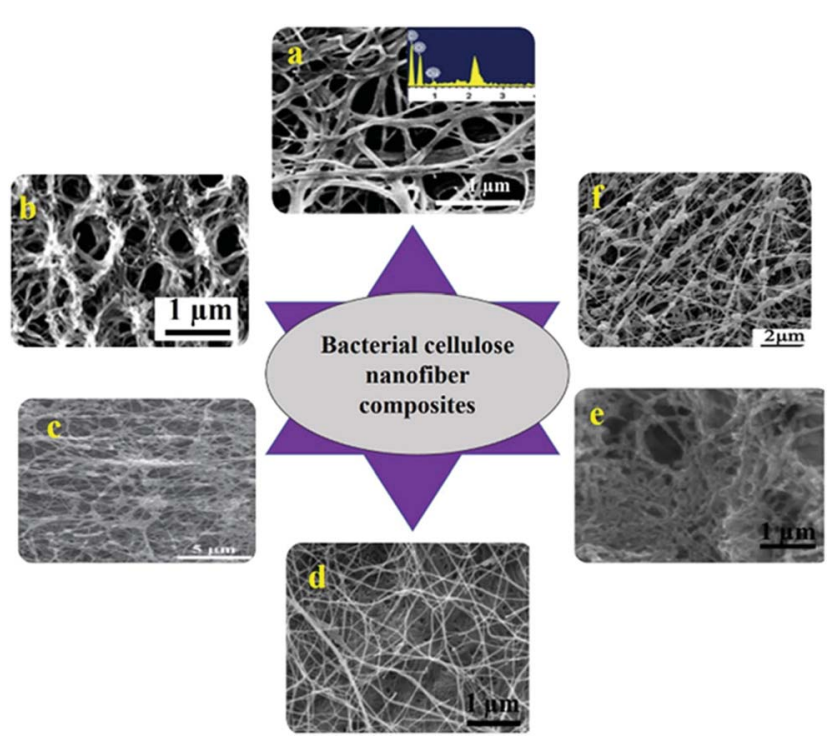

Fig. 4 SEM images of various nanocomposites made of bacterial cellulose (a) commercial BC/polyethylenimine nanofibers adsorbed with $\mathrm{Cu}^{2+}$ (ref. 105) (b) cross sectional image of PMMA grafted on BC nanofibers obtained from Gluconacetobacter sacchari ${ }^{106}$ (c) Acetobacter xylinum produced CNF coated with calcium phosphate ${ }^{107}$ (d) cytochrome C coated CNF processed from A. xylinum (ATCC $10245)^{108}$ (e) commercially obtained bacterial cellulose template synthesized carbon nanofiber ${ }^{104}$ (f) lecithin immobilized BC produced by $A$. xylinum X-2 (ref. 109) (all images were reproduced with permission).
The CNF composites has been prepared using in situ chemical polymerization technique, oxidative polymerization, freeze drying with in situ polymerization ${ }^{\mathbf{1 0 2}}$ and hydrothermal technique. Combination of plant derived CNF/carbon nanotubes/ PANI and CNF/carbon nanotubes/ $/ \mathrm{TiO}_{2}$ resulted in fibers with diameters of 10-30 nm while bacterial cellulose/carbon nanotubes resulted in fibers with 30-60 $\mathrm{nm}$ diameter. Association of CNF with fluorophores has been reported by Wang et al. ${ }^{\mathbf{1 0 5}}$ where CNF/1,4-dihydroxyanthraquinone (1,4-DHAQ) composite has been employed for effectively detecting $\mathrm{Cu}^{2+}$ and $\mathrm{Cr}^{3+}$ in contaminated water. ${ }^{\mathbf{1 0 5}}$

\subsection{Nanoparticle based CNF-composites}

CNF has been combined with various nanoparticles such as CdS nanoparticles, silver nanoparticles, hydroxyapatite (HAp) nanoparticles, gold nanoparticles etc. for catalytic applications. CNF with silver nanoparticles has been used as biosensors for the detection of catechol, ${ }^{\mathbf{1 0 6}}$ preparation of antibacterial fibers ${ }^{\mathbf{1 0 7}}$ and catalytic materials. ${ }^{\mathbf{1 0 8}}$ They have been prepared by wet reduction method using $\mathrm{NaBH}_{4}$, in situ chemical reduction and simple chemical binding techniques. In anti-bacterial fiber preparation, bacterial cellulose was doped with silver nanoparticle to obtain fibers of $1.5 \mathrm{~nm}$ that showed high resistance against the growth of Escherichia coli (E. coli) and Staphylococcus aureus (S. aureus). ${ }^{107} \mathrm{CNF}$ from natural cotton were reported to be functionalized with CdS nanoparticles by chemical bath deposition method for photocatalysis of organic pollutants. ${ }^{56}$ Briefly, the synthesis method consisted of soaking the electrospun $\mathrm{CNF}$ in $\mathrm{Cd}\left(\mathrm{NO}_{3}\right)_{2}$ ethanol solution followed by $\mathrm{Na}_{2} \mathrm{~S}$ solution each for $3 \mathrm{~min}$. It was further dried at $60^{\circ} \mathrm{C}$ to obtain $\mathrm{CdS} / \mathrm{CNF}$ of $100 \mathrm{~nm}$ diameter. Hap nanoparticles (HAp/CNF)

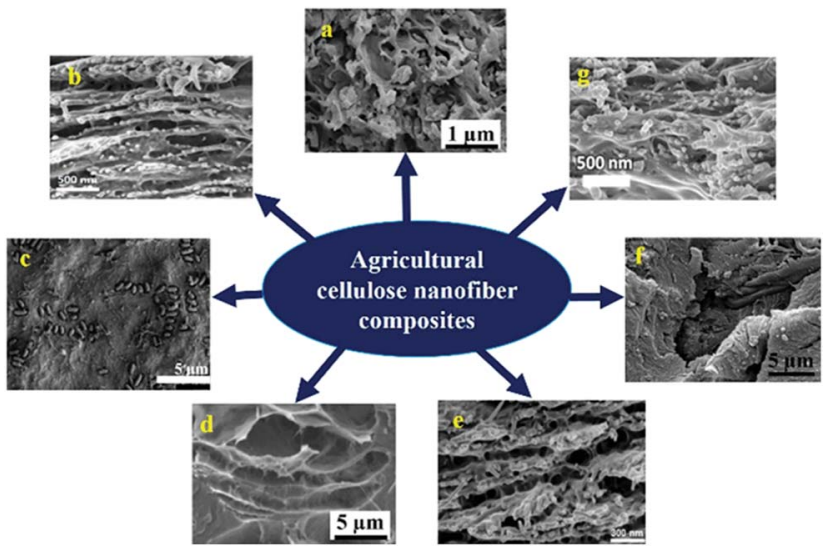

Fig. 5 SEM images of various nanocomposites delivered using plant CNF (a) softwood derived CNF and PLA blend ${ }^{110}$ (b) core shell nanofiber obtained by blending spruce sulphite pulp derived CNF and amylopectin (c) soft wood sulphite pulp derived nanofibrillated celluloseHEC composite ${ }^{119}$ (d) palm tree ranchis processed CNF and polyurethane blend ${ }^{172}$ (e) Core-shell image of hemicellulose and spruce sulphite pulp extracted CNF blend ${ }^{171}$ (f) Pinus sp. and Eucalyptus sp. extracted cellulose nanofiber-polyester blend ${ }^{173}(\mathrm{~g})$ composite obtained from 1-butyl-3-methylimidazolium chloride (BMIMCl) and canola straw derived $\mathrm{CNF}^{174}$ (all images were reproduced with permission). 
has been reported to be used for protein purification applications. Fig. 6 shows SEM images of various modified CNF based composites. Tian et al. ${ }^{\mathbf{1 0 9}}$ demonstrated the synthesis of HAp nanoparticles functionalized cellulose triacetate nanofibers for the purification of bovine serum albumin. The electrospun hybrid nanocomposite was reported to have a core (cellulose triacetate)-shell (HAp nanoparticles) structure with diameter of $346-816 \mathrm{~nm}$ and they exhibited high adsorption of BSA. ${ }^{109}$

\subsection{Synthesis of modified bacterial CNF}

Bacterial CNFs are well known for its characteristic properties such as high crystallinity, tensile strength, high surface area, nano sized network structure. ${ }^{\mathbf{1 1 0}}$ In order to further enhance their efficiency for various applications, CNFs surface has been modified using numerous functional groups. Various modification carried out with bacterial CNFs are provided in the following section.

\subsubsection{Polymer functionalization}

5.2.1.1 Amine. The surface modification of bacterial cellulose using amine groups were reported to enhance the surface area and adsorption capacity of the resulting modified CNF. Wang et al. ${ }^{\mathbf{1 1 0}}$ demonstrated the use of polyethyleneimine (PEI) surface functionalised bacterial CNF in the adsorption of heavy metal ions and organic dyes from contaminated water sources. They reported simple flush coating method followed by heat treatment for the functionalization of PEI on bacterial CNFs. The method comprised thorough washing of bacterial CNF membrane with sodium hydroxide $(0.1 \mathrm{M})$ at $100{ }^{\circ} \mathrm{C}$ followed by flushing the membrane with prepared PEI solution $(10.0 \mathrm{~g})$ under vacuum and later heating at $70{ }^{\circ} \mathrm{C}$ for $30 \mathrm{~min}$. The unbound PEI was removed from the surface of cellulose membrane by washing with deionised water followed by vacuum drying.

5.2.1.2 Aniline. To develop CNF based materials for various electronic applications, bacterial CNFs were functionalized using polyaniline that imparts the material excellent conductive properties. Such nanocomposite materials exhibited outstanding potential as supercapacitors. One such work has been reported by Wang et al. ${ }^{111}$ where pristine bacterial CNF obtained by shake culture method were surface polymerised with polyaniline. The preparation protocol included dispersion of synthesised bacterial CNF in solvent having combination of DMF and distilled water at $25{ }^{\circ} \mathrm{C}$. $1 \mathrm{~mL}$ of prepared aniline monomer was mixed vigorously with the cellulose suspension followed by cooling. This ensured self-assembly of aniline on the surface of the nanofibers. This was followed by the drop wise mixing of ammonium peroxide sulphate and hydrochloric acid mixture into the nanofiber suspension under constant stirring. The reaction was left to proceed overnight and allowed to precipitate which was filtered and washed with combination of acetone, water and $\mathrm{HCl}$. This was followed by drying overnight to achieve green coloured solid nanocomposite material, containing bacterial CNF of $30 \mathrm{~nm}$ size with flake morphology. The produced composite showed high electrical conductivity and enhanced surface area. ${ }^{\mathbf{1 0 2}}$ Similar protocol was adopted by $\mathrm{Hu}$ et al. ${ }^{\mathbf{1 1 2}}$ to develop bacterial CNF based flexible membranes that were surface coated with polyaniline nanoparticles. The synthesised nanocomposite membrane exhibited high thermal stability, electrical conductivity and excellent mechanical properties. Such conductive bacterial cellulose nanocomposite materials find extensive applications in flexible electronics such as electrodes, displays and sensors. ${ }^{\mathbf{1 1 2}}$ Likewise, Lin et al. ${ }^{\mathbf{1 1 3}}$ demonstrated the formation of bacterial cellulose-polyaniline film with single conductive side to be used in supercapacitors. The synthesis protocol of the nanocomposite film included initial wetting of bacterial cellulose film and wrapping it around a mould such as cup. The prepared aniline-toluene solution was then poured inside the mould. For $10 \mathrm{~min}$, the prepared mould was placed within the aniline monomer and ammonium persulphate solution which was maintained at $0{ }^{\circ} \mathrm{C}$ for 1 day that resulted in polyaniline formation at the bottom of the mould. Further the mould was removed from the APS solution. Using vacuum filtration, the aniline-toluene solution and remaining contents from within the mould were carefully removed. Mixture of acetone and distilled water was used to wash the inner region of the mould followed by vaccum drying for 1 day at $60{ }^{\circ} \mathrm{C}$. Later, the bacterial cellulose-polyaniline composite film with single phase coating was carefully obtained from the bottom of the mould. ${ }^{113}$

5.2.1.3 Methacrylate. Bacterial CNFs have immense applications as templates and scaffolds that assist cell growth in tissue regeneration. In order to enhance their suitability as scaffolds, these nanofibers were blended with various polymers such as methacrylates including acrylic acids, 2-ethylhexyl acrylate, 2-hydroxyethyl methacrylate which has high

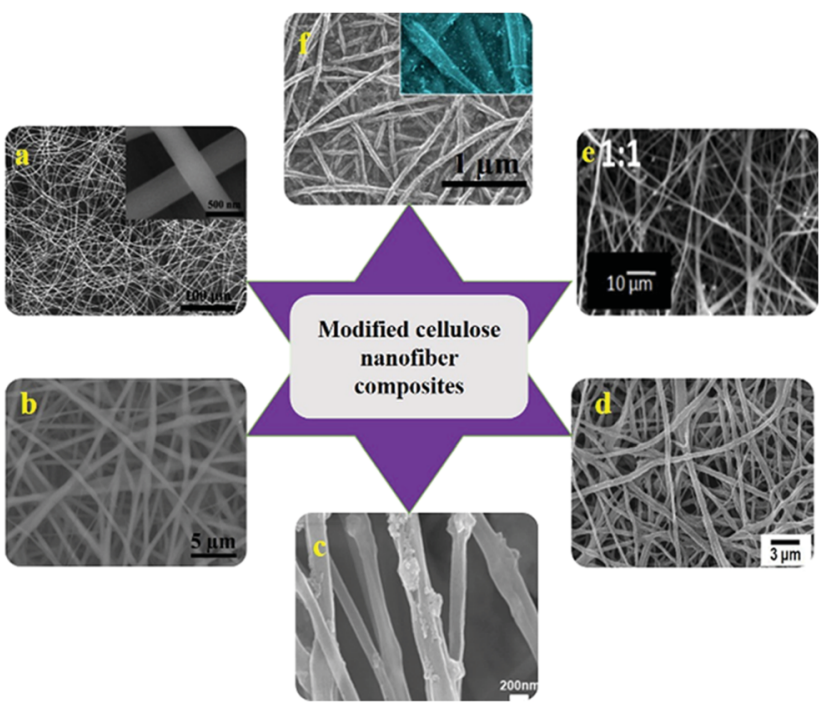

Fig. 6 Nanocomposites obtained using modified CNF (a) SEM image of cellulose acetate/1,4-DHAQ/CA nanofiber film (insert-high magnification image of cellulose acetate/1,4-DHAQ/CA nanofiber) ${ }^{175}$ (b) cellulose actetate-poly hydroxybutyrate blended nanofibers ${ }^{180}$ (c) hydroxyapatite decorated cellulose triacetate nanofibers ${ }^{179}$ (d) cellulose acetate nanofibers decorated with $\operatorname{AgNP}^{178}$ (e) cellulose actetatePCL blended nanofibers after deacetylation ${ }^{181}$ (f) polyamide layer coated on PAN/cellulose acetate nanofibers (inset (10 000x) image of polyamide surface) ${ }^{182}$ (all images were obtained with permission). 
biocompatibility with human cells and tissues. One such work has been reported by Hobzova et al. ${ }^{\mathbf{1 1 4}}$ where bacterial CNFmethacrylate composite hydrogels suitable for various tissue engineering applications were fabricated using simple polymerisation method. The CNFs were produced from Acetobacter xylinum sp. (sub species: sucrofermentas BPR2001) that was cultured in corn steep liquor medium and the synthesised nanofibers were maintained in swollen state. For the formation of composite hydrogels, the bacteria derived CNF sheets were immersed in the polymerisation mix at RT for 1 day in the presence of nitrogen gas under shaking condition. Later, discs were framed using silicone after carefully placing them on suitable glass substrate. A polypropylene plate was used to cover the sheets which were then closed in to a mould using appropriate clamps. This was followed by $20 \mathrm{~min}$ exposure to UV illumination for polymerisation. The compound thus formed was carefully removed from the mould and washed consecutively for 5 days using distilled water. ${ }^{115}$ Apart from the biological applications, bacterial CNFs with methacrylates also find suitable applications in flexible electronics. Nogi and Yano ${ }^{\mathbf{1 1 5}}$ reported the fabrication of thermally stable and foldable flat panel display (FPD) by reinforcing acrylic resin with bacterial CNFs. In their work, A. xylinum FF-88 was used to produce CNFs under static conditions. The cellulose pellicle obtained after 10 days were purified by boiling in $\mathrm{NaOH}$ for $2 \mathrm{~h}$ with subsequent washing using water for 2 days. The final product obtained was compressed and immersed in ethanol : water solution (50\%) and the content of ethanol was gradually increased until 100\% to completely replace the solvent present in the cellulose pellicle. Further, the acrylic resin was impregnated with the CNF pellicle for $12 \mathrm{~h}$ under pressure of $0.09 \mathrm{MPa}$. Ultraviolet curing was finally carried out to cure the resin. ${ }^{115}$ Similar method of solvent exchange was adopted by Kramer et al. ${ }^{\mathbf{1 1 6}}$ for the fabrication of nanocomposites where bacterial CNFs were photopolymerised with methacrylate and acrylate via methacrylate crosslinking. The CNFs were obtained by the static culture of G. xylinus (strain: DSM 14666) and the developed composite material exhibited collagen like properties such as high water absorption, elasticity, biocompatibility, nanofibrous structure and modifiable pore size. ${ }^{\mathbf{1 1 6}}$

5.2.1.4 Poly vinyl alcohol (PVA). The combination of bacterial CNFs with PVA resulted in nanocomposites with extraordinary mechanical strength, thermal stability and toughness. Bacterial CNF-PVA hydrogel was synthesised by mixing PVA powder to the nanofibrillated suspension with distilled water and stirred for $2 \mathrm{~h}$ at $85{ }^{\circ} \mathrm{C}$ in the presence of a crosslinker, gluteraldehyde. ${ }^{\mathbf{1 0}}$ The obtained hydrogel was washed in deionised water and the surface water content of the hydrogel was removed by gentle tapping using a clean filter paper. ${ }^{10}$ Likewise, Millon and Wan $^{\mathbf{1 1 7}}$ optimised protocol for fabricating bacterial CNF-PVA composite hydrogel as replacement for cardiovascular tissues. In his protocol, A. xylinum was cultured to synthesise cellulose fibers in nano size ranges. CNF-PVA composite solution was prepared according to the method reported by L. Yang et $a l .{ }^{10}$ Further, this solution was transferred into appropriately designed moulds of aluminium and was placed in a refrigerator $\left(0.1{ }^{\circ} \mathrm{C} \mathrm{min}^{-1}\right)$ with multiple freeze and thaw cycles. His group has also demonstrated the efficiency of bacterial CNF-PVA composite material developed for cartilage replacement following the same protocol. ${ }^{117}$

5.2.1.5 Poly ethylene oxide (PEO). Bacterial CNF in combination with $\mathrm{PEO}$ resulted in high quality nanocomposites useful for various applications. Brown et al. ${ }^{\mathbf{1 1 8}}$ fabricated stable and flexible thermoplastic material using bacterial CNF from $A$. xylinum and PEO. Briefly, A. xylinum 23769 was inoculated and maintained in autoclaved HS medium of pH 5.0. The bacterial culture was carried out under static conditions. The cellulose pellicle formed in the medium after one week of culturing was obtained carefully and processed. Later, this was inoculated into a separate HS medium containing PEO. After two days of static maintenance, the cellulose pellicle obtained was carefully removed. The leftover medium was cultured again under agitation of $500 \mathrm{rpm}$. After two days of culture, the strings of cellulose formed was collected carefully using a gauge and washed multiple times using deionised water. ${ }^{118}$

\subsubsection{Metal functionalization}

5.2.2.1 Palladium. Metal particles were doped on the surface of bacterial CNFs to enhance its properties for various applications. Such surface metal doping enhanced the mechanical features and stability of the resulting CNF structure. For instance, bacterial CNF doped palladium has been proved to be an efficient catalyst for Heck coupling by Zhou et al. ${ }^{\mathbf{1 1 9 , 1 7 8}}$ The preparation protocol involved hydrothermal reduction method where palladium particles were physically coated on the surface of bacterial CNFs. In detail, $\mathrm{PdCl}_{2}$ was mixed well with the aqueous solution of bacterial CNFs followed by degassing the solution for $30 \mathrm{~min}$ and subsequent heating under the influence of $\mathrm{N}_{2}$ at $140{ }^{\circ} \mathrm{C}$ for $5 \mathrm{~h}$ with constant stirring. Further, aqueous solution of potassium borohydride was added into the mixing solution and was allowed to mix at $80{ }^{\circ} \mathrm{C}$ for $3 \mathrm{~h}$ after which, it was subjected to multiple cycles of centrifugation and washing resulting in black coloured nanocomposite. ${ }^{119}$

5.2.2.2 Silver. Bacterial CNFs were also stable templates for the surface doping of silver particles. This enhances the stability, conductivity and mechanical performance of the resulting CNFs. This was explored by Ifuku et al. ${ }^{120}$ where he and his co-workers synthesised bacterial CNFs using TEMPO mediated oxidation. The ion exchange reaction between the added $\mathrm{Ag}$ particles and the carboxylate groups on the fiber surface resulted in the attachment of $\mathrm{Ag}$ particles on the CNF. This was followed by metal reduction on to the surface as fine $\mathrm{Ag}$ nanoparticles. In detail, prepared bacterial cellulose fibrous sheets were immersed in aqueous solution of TEMPO and sodium bromide. To initiate oxidation reaction, sodium hypochlorite solution was introduced to the solution and the reaction was proceeded overnight at $\mathrm{pH}$ 10.5. Ethanol was later added to the solution as quencher to stop the reaction. The product was then dried overnight at $65{ }^{\circ} \mathrm{C}$. In order to coat the bacterial CNF surface with Ag nanoparticles, prepared nanofiber was immersed in aqueous solution of $\mathrm{AgNO}_{3}$ at RT in dark and the reaction was allowed to proceed overnight. The reduction reaction was performed at $100{ }^{\circ} \mathrm{C}$ for $1 \mathrm{~h}$ under RT. ${ }^{\mathbf{1 2 0}}$

5.2.2.3 Gold. Bacterial CNFs are well known for their association with gold nanoparticles (AuNP). Chen et al. ${ }^{121}$ 
demonstrated the efficiency of bacterial CNF as templates for the growth of AuNP on their surface. The developed nanocomposite was reported to have high catalytic activity towards the reduction of 4-nitrophenol and was proposed to have wide range of industrial applications. In this work, CNFs were obtained from G. xylinum and were made in to a suspension using deionised water using a supercollider. Chen $e t$ al. introduced a two-step method for preparing the CNF substrate for AuNP production. Initially, cellulose activation was done by dispersing it in $\mathrm{NaOH}$ solution for $7 \mathrm{~h}$. Further, under constant stirring conditions, acrylonitrile was gradually added at RT and the reaction was allowed to proceed for $12 \mathrm{~h}$. Later, cycles of centrifugation and washing were carried out to obtain cyano ethyl surface modified bacterial cellulose. This was followed by dispersion of surface functionalised cellulose in a solution of $\mathrm{NH}_{4} \mathrm{OH} / \mathrm{NaOH}: \mathrm{HCl}$ for $10 \mathrm{~h}$ at $50{ }^{\circ} \mathrm{C}$. This resulted in amidoxime surface functionalised $\mathrm{CNFs}$ (AOBC). The obtained cellulose fibers were purified from other components by multiple rounds of centrifugation-washing, followed by freezedrying. The freeze-dried AOBC was dispersed in deionised water containing aqueous solution of $\mathrm{HAuCl}_{4}$. This was further transferred into $110^{\circ} \mathrm{C}$ hot oil bath and stirred for $2 \mathrm{~h}$ resulting in a pink-purple solution. To obtain CNF-AuNP precipitate, the solution in oil bath was centrifuged and the resulting pellet was washed multiple times using deionised water. ${ }^{121}$

5.2.2.4 Carbon functionalization. Bacterial CNF also find extensive usage as templates for the synthesis of high stability electrode materials when doped with carbon for various applications including batteries. One such work has been reported by Zhang et al ${ }^{104}$ where his group developed carbon nanofiber doped nitrogen electrodes using bacterial $\mathrm{CNF} /$ polypyrrole precursor for sodium ion batteries. Briefly, Zhang et al. fabricated bacterial CNF precursor by surface assembly of polypyrrole on to the nanofibers via polymerisation. The bacterial CNFs were obtained by high speed mechanical homogenisation of bacterial pellicles and deionised water for $20 \mathrm{~min}$. To this suspension, $\mathrm{HCl}$ and ferric chloride solution was introduced and sonicated for $15 \mathrm{~min}$. Later, pyrrole solution was added into the mixture at $1-5{ }^{\circ} \mathrm{C}$, mixed well for $15 \mathrm{~min}$ and the reaction was allowed to proceed for $5 \mathrm{~h}$. The resulting precipitate was freeze dried under vacuum overnight and finally heated at $700{ }^{\circ} \mathrm{C}$ for $3 \mathrm{~h}$ in the presence of argon gas. ${ }^{104}$ Similarly Chen et al. ${ }^{122}$ has reported the fabrication of bacterial cellulose derived carbon nanofibers for supercapacitor applications. In his work, bacterial cellulose based carbon nanofibers were doped with heteroatom to enhance the performance of the resulting material. The rectangular pieces of bacterial cellulose pellicles were immersed in aqueous solution of $\mathrm{H}_{3} \mathrm{PO}_{4}$, $\mathrm{HN}_{4} \mathrm{H}_{2} \mathrm{PO}_{4}$ and $\mathrm{H}_{3} \mathrm{BO}_{3} / \mathrm{H}_{3} \mathrm{PO}_{4}$ for $10 \mathrm{~h}$ at RT under constant stirring followed by liquid nitrogen freezing. This is trailed by freeze drying at $-50{ }^{\circ} \mathrm{C}$. The pyrolization of bacterial cellulose was carried out at $2-520{ }^{\circ} \mathrm{C}$ in the presence of $\mathrm{N}_{2}$ gas for $1 \mathrm{~h}$ followed by $5-800{ }^{\circ} \mathrm{C}$ for $1 \mathrm{~h}$ resulting in the carbon material. ${ }^{122}$ Chen et al. ${ }^{123}$ reported the development of bacterial CNF embedded multi-walled carbon nanotubes (MWCNT) for various medical, electrical and mechanical applications. Initially, bacterial cellulose hydrogels were prepared by culturing G. xylinum BRC5 in HS medium which was later freeze dried and cut in to appropriately sized pieces. This was stored at $25^{\circ} \mathrm{C}$ in vacuum oven for $3 \mathrm{~h}$. Later the content was added into 1-allyl-3-methyl-imidazolium chloride solution at $70{ }^{\circ} \mathrm{C}$ with constant stirring and introduced with dimethyl sulphoxide solution at RT. To the solution added $0.02 \%$ MWCNT under constant stirring for $3 \mathrm{~h}$ to obtain a homogenous solution for electrospinning. Finally, CNF with MWCNTs nanocomposite mats were obtained after vacuum drying the electrospun composite membranes washed with ethanol and deionised water. ${ }^{123}$

\section{Applications}

CNF and its composites from plant and bacterial cellulose has immense applications in various fields like purification of waste water, scaffold substrate for tissue engineering, as drug carrying vehicles for sustained and targeted delivery, cationic and anionic electrodes and as edible coatings for food packaging. A brief account of their application is provided in Table 2. Some of their major applications have been discussed in detail in the following sections.

\subsection{Water purification}

CNFs of both bacterial and agricultural origin have been used for efficient heavy metal remediation for the conversion of waste water into reusable form. Properties such as high specific surface area, nano size, non-toxicity, hydrophilicity, bio adsorption ability etc. makes them suitable candidates to be used as water purifying biomembranes. ${ }^{124,179,181}$ Liu et al. ${ }^{124}$ reported a super-hydrophilic $\mathrm{Cu}$ (II) ion adsorbing CNF membrane for the remediation of industrial effluents. In their work, CNF were synthesised via TEMPO mediated oxidation of cellulose sludge obtained from agricultural waste and the developed nanofibers were in the size range of $18-40 \mathrm{~nm}$ with high specific surface area which was in the range of $134-215 \mathrm{~g} \mathrm{~m}^{-2}$. They modified the surface of the CNFs using carboxylate groups in the concentration range of $0.6 \mathrm{mmol} \mathrm{g}^{-1}$ and $1.5 \mathrm{mmol} \mathrm{g}^{-1}$. They reported that the interaction of surface carboxylate groups with the $\mathrm{Cu}(\mathrm{II})$ ions from the effluents leads to the adsorption of $\mathrm{Cu}$ ions on to the surface of nanofiber membrane with their gradual and subsequent conversion in to $\mathrm{Cu}$ oxide nanoparticles with a size ranging from $200-300 \mathrm{~nm}$. This conversion further enhanced the efficiency and robustness of water purification using the biomembrane. The nanofiber membrane exhibited maximum $\mathrm{Cu}$ ion adsorption capacity of $75 \mathrm{mg} \mathrm{g}^{-1}{ }^{124}$ Similarly, Meiling et al. ${ }^{125}$ has reported the fabrication of fluorescent cellulose acetate nanofibers for the detection of $\mathrm{Cu}^{2+}$ and $\mathrm{Cr}^{3+}$ from polluted water source based on fluorescence. They developed electrospun cellulose acetate nanofibers doped with fluorophore 1,4-dihydroxyanthraquinone (1,4-DHAQ) and demonstrated the changes occurring in the fluorescence intensity of the nanofibers with the adsorption of $\mathrm{Cu}^{2+}$ and $\mathrm{Cr}^{3+}$. The fluorescence intensity of the fabricated CNFs were reported to be reducing with increasing adsorption of $\mathrm{Cu}^{2+}$ due to the formation of phenolate whereas, increasing concentration of 
$\mathrm{Cr}^{3+}$ enhanced the fluorescence intensity of the CNF template. The maximum $\mathrm{Cu}^{2+}$ adsorption capacity of the nanofiber was reported to be in the range of $2.5 \times 10^{-9} \mathrm{M}$ to $3.75 \times 10^{-8} \mathrm{M}^{125}$

In another study, Snyder et al. ${ }^{126}$ showed the potential of Eucalyptus pulp derived CNF doped with $\mathrm{TiO}_{2}$, $\mathrm{Au}$ and $\mathrm{Ag}$ particles in effective removal of organic compound, methylene blue from contaminated water source. They demonstrated that the photocatalytic activity of $\mathrm{TiO}_{2}-\mathrm{CNF}$ enhanced with the surface functionalization of $\mathrm{Au}$ and $\mathrm{Ag}$ particles in the presence of simulated sunlight. ${ }^{117}$ Cellulose acetate nanofibers modified using oxolane-2,5-dione has also been reported as excellent adsorbents of heavy metal ions such as lead and cadmium from contaminated water sources by Stephen $e t$ al. ${ }^{127}$ The developed CNF composite exhibited high reusable capacity without compromising its adsorption efficiency. ${ }^{127} \mathrm{CNF}$ based aerogels has also been successfully employed in decontamination of water. Xu He et al. ${ }^{128}$ demonstrated the efficiency of chemically crosslinked, highly porous CNF aerogels functionalised with ammonium in remediating $\operatorname{Cr}(\mathrm{Iv})$ ions from waste water. They reported that $99 \%$ of $\mathrm{Cr}(\mathrm{Iv})$ ions from $1 \mathrm{~L}$ of contaminated water was successfully remediated using $1 \mathrm{~g}$ of CNF aerogel. ${ }^{128}$ In another study, Sehaqui et al. ${ }^{92}$ used waste pulp derived $\mathrm{CNF}$ for efficient removal of $\mathrm{PO}_{4}{ }^{3-}, \mathrm{SO}_{4}{ }^{2-}, \mathrm{F}^{-}$and $\mathrm{NO}^{3-}$ from polluted water source. They demonstrated the transformation of CNFs to cationic CNFs by the surface functionalization of quaternary ammonium. The developed CNF paper showed high potential towards nitrate removal $\left(380 \mathrm{mg} \mathrm{m}^{-2}\right)$ when compared to other anions present in the contaminated water. ${ }^{92}$ Similar to the plant derived and modified CNF, bacterial originated CNFs also acted as potential bioadsorbant agents in water purification. Bhavna, Mohite and Patil ${ }^{95}$ reported that cellulose obtained from $\mathrm{Glu}$ conacetobacter hansenii successfully removed heavy metal ions such as $\mathrm{Pb}^{2+}, \mathrm{Cd}^{2+}$ and $\mathrm{Ni}^{2+}$. They also showed the potential of bacterial $\mathrm{CNF}$ in removal of azo dyes resulting in clean environment. ${ }^{95}$ Similarly, Wang et al. ${ }^{105}$ reported the fabrication of $\mathrm{Cu}^{2+}$ and $\mathrm{Pb}^{2+}$ adsorbing biomembranes made of bacterial CNFs coated with polyethylenimine using flush coating technique for purification of waste water. The fabricated membrane exhibited superior adsorption and desorption capacity after acid treatment using ethylene diamine tetra acetic acid and better recycling ability. A unique feature of this biomembrane is reported to be their ability to adsorb $\mathrm{Cu}^{2+}$ ions, their subsequent reduction into copper nanoparticles which further catalyses the reduction of methylene blue dye from aqueous solutions. ${ }^{110}$ CNFs were also used to separate oil and organic contaminants from water. One such study was reported by Huazheng Sai et al. ${ }^{129}$ where CNFs derived from bacteria was used as oil adsorbents from water sources. They used a method in which the nanofiber was surface modified using trimethylchlorosilane to obtain CNFs with hydrophobicity. The resulting nanofibers exhibited well defined porous structure with high surface area and oil absorption ability of $185 \mathrm{~g} \mathrm{~g}^{-1} .129$

\subsection{Tissue engineering and drug delivery}

CNFs also find extensive applications in the area of bone, cartilage and skin tissue engineering due to its large surface area, tuneable pore size, non-toxicity, biocompatibility, biodegradability and superior mechanical strength. In addition, their ability to deliver the bioactive compounds in sustained manner along with tuneable surface properties spikes their demand as effective drug carriers in targeted drug delivery. In a study carried out by Nasri-Nasrabadi et al. ${ }^{130}$ starch/cellulose composite nanofibers were used to fabricate porous scaffolds for cartilage tissue engineering. In this method, $\mathrm{NaCl}$ was used as the porogen to develop suitable pore size in the nanofibers which impart enhanced surface properties to the scaffold. The incorporation of higher content of CNF was reported to enhance the tensile strength, Young's modulus and hydrophilicity of the resulting scaffold. They also reported slow degradation of the fabricated scaffold in vitro ( $>20$ weeks) along with enhanced rabbit chondrocyte attachment and proliferation. ${ }^{130}$ Likewise, CNFs derived from bacterial sources are also used to develop scaffolds as substrates suitable for cell attachment and proliferation. One such bacterial CNF based porous scaffold was developed by Zhang et al. ${ }^{131}$ They reported A. xylinum X-2 extracted CNF surface immobilised with lecithin which was further crosslinked with proanthocyanidin. The developed scaffold exhibited superior mechanical strength, hydrophilicity, cytocompatibility, porosity and thermal stability. ${ }^{131}$ Modified cellulose such as cellulose acetate, hydroxypropyl cellulose and hydroxymethyl cellulose also exhibited remarkable potential to be used in tissue engineering. Chahal et al. ${ }^{132}$ fabricated modified cellulose-PVA blended electrospun nanofiber based scaffold for bone tissue engineering. High mechanical properties, stability, bead free morphology of the nanofiber, biocompatibility and biodegradability are some of the highlighting features of this scaffold. ${ }^{132}$ Qiao et al. ${ }^{133}$ developed highly porous composite hydrogels made of bacterial CNFs and PVA and studied their mechanical properties to understand their suitability for various biomedical applications. Their high crystallinity, superior tensile strength and Young's modulus makes them highly recommended substrate for wound dressing and for the synthesis of artificial blood vessels and cartilage. ${ }^{133}$

Modified CNFs also acted as suitable drug carriers. Hydrophobic drugs such as sulfisoxazole encapsulated hydroxy propyl- $\beta$-cyclodextrin incorporated hydroxy propyl CNFs were fabricated to develop sustainable drug delivery system. ${ }^{134}$ The release of sulfisoxazole from the developed nanofiber material was prolonged up to $720 \mathrm{~min}$. High surface area, enhanced solubility of the drug, controlled drug delivery and biocompatibility makes them a potential choice as wound dressing material. Similarly, Opanasopit et al. ${ }^{135}$ reported the fabrication of transdermal patches containing cellulose acetate and PVA nanofibers incorporated with capsicum extract. The developed material showed high skin permeation while tested on shed snake skin as the model and superior cytocompatibility while studied on normal human foreskin fibroblast cells (NHF). ${ }^{135}$

\subsection{Food packaging}

CNFs are used as edible coatings to preserve the shelf life of various fruits and vegetables. They carry out this function by reducing the microbial growth on the fruits and vegetables, 
oxidation and by reducing the transfer of moisture thereby maintaining the quality of the products. ${ }^{136}$ Andrade et al. ${ }^{136}$ reported a study on the viscosity and spreading dynamics of the edible coating formulation developed using CNFs along with glycerol and gelatin on the surface of banana and eggplant epicarps. They reported the development of drop method using a high speed syringe pump to produce the coating on the surface of the fruits. The CNF used for this application was obtained from Gluconacetobacter swingsii and pineapple peel juice. They prepared the formulation by initially hydrating gelatin in $100 \mathrm{~mL}$ of distilled water at RT for $30 \mathrm{~min}$ in the concentration range of $0.6,1.3$ and $2 \mathrm{~g}$. After complete dissolution of gelatin, CNF and glycerol was added in the concentration range of $1 \mathrm{~g}, 5 \mathrm{~g}$ and $10 \mathrm{~g}, 20 \mathrm{~g}$ per $100 \mathrm{~g}$ of gelatin respectively. Finally, the mix was sonicated for $30 \mathrm{~min}$. SitiHajar Othman, ${ }^{137}$ Vijayendra and Shamala, ${ }^{138}$ Tang et al. ${ }^{139}$ and Babak Ghanbarzadeh et al. ${ }^{140}$ has reviewed in detail the role of CNF along with other biopolymers as nanofillers and reinforcing agent to enhance the mechanical properties, duration and stability of the resulting coating material. Panaitescu et al. ${ }^{141}$ also reported the use of CNF based materials for food packaging. In his work, CNF obtained from microcrystalline cellulose was used as reinforcing agent in starch/PVA composite films, which was further tested for its efficacy as food packaging films. It was reported that addition of CNF enhanced mechanical strength and stability of the composite polymer films. ${ }^{141}$

$\mathrm{CNF}$ are also used as reinforcing agents in food packaging material. The applications of food packaging materials available commercially are limited due to its poor mechanical properties. Incorporation of CNF enhances the efficiency of the fabricated edible materials for packing the foods. The potential of CNFs as reinforcing agents in developing edible coatings for fruits and vegetables are reported by Azeredo et al. ${ }^{142}$ They tried to develop edible films of mango puree incorporated with CNFs. The presence of cellulose fibers are reported to enhance the mechanical properties such as tensile strength and elastic modulus of the fabricated film. The cellulose fibers also reduced the permeability of water vapour thereby ensuring high stability of the composite edible film produced. ${ }^{\mathbf{1 4 2}}$

\subsection{Miscellaneous applications}

CNFs find extensive application as energy storage devices. Yang et al. ${ }^{143}$ reported the fabrication of super capacitor electrodes using CNF and multi walled carbon nanotubes (MWCNT) surface coated using polyaniline. The resulting porous aerogel capacitor electrode exhibit minimum charge transfer resistance, super specific capacitance, flexibility and are cost effective. ${ }^{143}$ Similarly, Wang and $\mathrm{Li}^{103}$ developed foldable hybrid supercapacitor electrode using CNF coated with MWCNTs and $\mathrm{TiO}_{2}$ nanotubes. The resulting electrode exhibited high mechanical strength, flexibility, enhanced discharge capacity and superior cyclability. ${ }^{103}$ Bacterial CNF based electrode has been fabricated for sodium ion batteries by Zhang et al. ${ }^{104}$ Superior reversible specific capacity, high stability and excellent electrochemical activities are outstanding features of this electrode. ${ }^{104} \mathrm{CNFs}$ are also used as agents to identify adulterants in cosmetics and pharmaceutical products. Tidjarat et al. ${ }^{144}$ reported the use of cellulose acetate nanofibers as screening agents to identify the adulterations in retinoic acid and hydroquinone present in the cosmetic products using chromatographic technique. ${ }^{144} \mathrm{~A}$ similar study using cellulose acetate was also reported by Rojanarata et al. ${ }^{145}$ in identifying the adulterations in steroid present in various nutraceuticals and pharmaceuticals. ${ }^{145}$

\section{Conclusions}

This review presents various techniques employed for the extraction of CNF from plants and bacterial sources. The study suggests that the extraction of homogenous CNFs from different plant sources such as rice, wheat straw, wood, banana, cotton, sea grasses etc. are feasible but accompanied with certain drawbacks. It is critical to choose an apt treatment method for their isolation. It is important to employ an ecofriendly extraction technique that results in high mechanical strength and integrity of the resulting CNF along with purity, biocompatibility, crystallinity, wettability and surface tuneable structure. The properties of CNF are very unique and specific to the extraction method employed thereby making them complementary to each other. In case of extracting CNF from plant sources, a combination of mechanical, physical, chemical and enzymatic treatment results in better yield than adopting a single treatment option. The use of mechanical disintegration techniques such as homogeniser and microfluidizer are limited due to disadvantages like fiber clogging and requirement of high energy source. Thus for the high scale production of CNF, oxidation of fibers prior to their exposure to mechanical treatment, results in easier defibrillation. The isolation of CNF from bacterial sources is comparatively easier and results in high purity CNF. However, the duration required for the production of complete CNF limits their benefits in the industrial scale. Thus there is a need to develop a technique that provides high yield of pure CNF within short span of time. In addition to this, the properties of CNF specific for particular applications can be customised by blending them with various hydrophilic and hydrophobic polymers. Surface doping of CNF with metals, non-metals and numerous nanoparticles are also addressed in this review. To recapitulate, this review converges the different extraction strategies employed for the isolation of CNF from various plant and bacterial species.

\section{Conflicts of interest}

There are no conflicts to declare.

\section{Abbreviations}

CNF Cellulose nanofiber

CNC Cellulose nanocrystal

hDFC Human dental follicle cells

RhB Rhodamine B

TFNC Thin film nanofibrous composite 
DTPA Diethylene triamine penta acetic acid

TEMPO 2,2,6,6-Tetramethylpiperidin-1-yl)oxy radical oxidation

$\mathrm{NaOH}$ Sodium hydroxide

$\mathrm{KOH}$ Potassium hydroxide

FDP Flat panel display

DHAQ Dihydroxy anthraquinone

HAp Hydroxyapatite

AOBC Amidoxime surface functionalised CNF

MWCNT Multi wall carbon nanotube

\section{Acknowledgements}

The authors of this paper acknowledge PSG Institute of Advanced Studies and PSG Management, Coimbatore, India, for supporting this review work.

\section{References}

1 D. Klemm, B. Heublein, H. P. Fink and A. Bohn, Angew. Chem., Int. Ed., 2005, 44, 3358-3359.

2 H. A. Khalil, A. H. Bhat and A. I. Yusra, Carbohydr. Polym., 2012, 87, 963-979.

3 I. N. Siró and D. Plackett, Cellulose, 2010, 17, 459-494.

4 J. Bras, D. Viet, C. Bruzzese and A. Dufresne, Carbohydr. Polym., 2011, 84, 211-215.

5 R. J. Moon, A. Martini, J. Nairn, J. Simonsen and J. Youngblood, Chem. Soc. Rev., 2011, 40, 3941-3994.

6 E. M. Teixeira, A. C. Corrêa, A. Manzoli, A. F. L. Leite, C. R. Oliveira and L. H. Mattoso, Cellulose, 2010, 17, 595-606.

7 D. N. Saheb and J. P. Jog, Adv. Polym. Technol., 1999, 18, 351-363.

8 S. T. Georgopoulos, P. A. Tarantili, E. Avgerinos, A. G. Andreopoulos and E. G. Koukios, Polym. Degrad. Stab., 2005, 90, 303-312.

9 T. Subbiah, G. S. Bhat, R. W. Tock, S. Parameswaran and S. S. Ramkumar, J. Appl. Polym. Sci., 2005, 96, 557-569.

10 L. Yang, Z. Hong-Yu, Q. Yang and L. Da-nian, J. Appl. Polym. Sci., 2012, 126, 244-250.

11 A. Sato, D. Kabusaki, H. Okumura, T. Nakatani, F. Nakatsubo and H. Yano, Composites, Part A, 2016, 83, 72-79.

12 L. Heath and W. Thielemans, Green Chem., 2010, 12, 14481453.

13 S. Beck-Candanedo, M. Roman and D. G. Gray, Biomacromolecules, 2005, 6, 1048-1054.

14 M. Samyn, P. Laborie, A. P. Mathew, A. Airoudj, H. Haidara and V. Roucoules, Langmuir, 2012, 28, 1427-1438.

15 M. Pääkkö, M. Ankerfors, H. Kosonen, A. Nykänen, S. Ahola, M. Österberg, J. Ruokolainen, J. Laine, P. T. Larsson, O. Ikkala and T. Lindström, Biomacromolecules, 2007, 8, 1934-1941.

16 P. Podsiadlo, S. Y. Choi, B. Shim, J. Lee, M. Cuddihy and N. A. Kotov, Biomacromolecules, 2005, 6, 2914-2918.

17 B. Soni, E. B. Hassan and B. Mahmoud, Carbohydr. Polym., 2015, 134, 581-589.
18 G. F. Torres, S. Commeaux and O. P. Troncoso, J. Funct. Biomater., 2012, 3(4), 864-878.

19 M. Jonoobi, et al., Compos. Sci. Technol., 2010, 70(12), 17421747.

20 A. N. Frone, et al., J. Mater. Sci., 2016, 51(21), 9771-9791.

21 N. Najib and C. Christodoulatos, Proceedings of the 13th International Conference of Environmental Science and Technology, Athens, Greece, 2013.

22 M. Labet and W. Thielemans, Cellulose, 2011, 18(3), 607617.

23 Y. Luo, J. Zhang, X. Li, C. Liao and X. Li, J. Nanomater., 2014, 2014, 11.

24 J. I. Morán, V. A. Alvarez, V. P. Cyras and A. Vázquez, Cellulose, 2008, 15, 149-159.

25 W. Chen, Q. Li, J. Cao, Y. Liu, J. Li, J. Zhang, S. Luo and H. Yu, Carbohydr. Polym., 2015, 117, 950-956.

26 A. N. Nakagaito and H. Yano, Appl. Phys. A: Mater. Sci. Process., 2004, 78, 547-552.

27 I. M. Saito, C. Cabello and R. S. Fukushima, Revista Raízes e Amidos Tropicais, 2006, 2, 1-11.

28 K. Ohkawa, Molecules, 2015, 20, 9139-9154.

29 R. Dashtbani and E. Afra, Int. J. Nano Dimens., 2015, 6, 1.

30 J. S. Eichhorn, et al., J. Mater. Sci., 2010, 45(1), 1.

31 C. C. Jose, L. Mathew and S. Thomas, Rev. Adv. Mater. Sci., 2014, 37, 1.

32 W. Haoran, et al., Environ. Sci.: Nano, 2014, 1(4), 302-316.

33 O. Nechyporchuk, M. N. Belgacem and J. Bras, Ind. Crops Prod., 2016, 93, 2-25.

34 M. Albert, J. Appl. Polym. Sci., 2011, 119(4), 2449-2460.

35 J. Olivier, et al., Nature, 2000, 408, 157.

36 N. Shahid, D. R. Hahn and G. Schuurman, Nature, 2000, 403, 762 .

37 N. W. Scott, Ambio, 1990, 101.

38 E. Nicolai and R. D. Preston, Proc. R. Soc. London, Ser. B, 1952, 140(899), 244-274.

39 M. Pääkkö, J. Vapaavuori, R. Silvennoinen, H. Kosonen, M. Ankerfors, T. Lindström, L. A. Berglund and O. Ikkala, Soft Matter, 2008, 4(12), 2492-2499.

40 H. Noriko, T. Kondo and M. Ishihara, Carbohydr. Polym., 2005, 61(2), 191-197.

41 R. Ek, C. Gustafsson, A. Nutt, T. Iversen and C. Nyström, J. Mol. Recognit., 1998, 11(1-6), 263-265.

42 A. Mihranyan, A. P. Llagostera, R. Karmhag, M. Strømme and R. Ek, Int. J. Pharm., 2004, 269(2), 433-442.

43 M. Johnson, S. Shivkumar and L. Berlowitz-Tarrant, Mater. Sci. Eng., B, 1996, 38(1), 103-108.

44 E. A. Bayer, H. Chanzy, R. Lamed and Y. Shoham, Curr. Opin. Struct. Biol., 1998, 8(5), 548-557.

45 C. O'sullivan Antoinette, Cellulose, 1997, 4(3), 173-207.

46 T. Ioannes, J. Phycol., 1999, 35(4), 635-655.

47 N. Hayashi, J. Sugiyama, T. Okano and M. Ishihara, Carbohydr. Res., 1997, 305(1), 109-116.

48 M. Albert, K. Edsman and M. Strømme, Food Hydrocolloids, 2007, 21(2), 267-272.

49 G. Nyström, A. Razaq, M. Strømme, L. Nyholm and A. Mihranyan, Nano Lett., 2009, 9(10), 3635-3639. 
50 M. M. Andrade-Mahecha, F. M. Pelissari, D. R. TapiaBlácido and F. C. Menegalli, Carbohydr. Polym., 2015, 123, 406-415.

51 I. K. Neelamana, S. Thomas and J. Parameswaranpillai, J. Appl. Polym. Sci., 2013, 130, 1239-1246.

52 E. M. Teixeira, A. C. Corrêa, A. Manzoli, A. F. L. Leite, C. R. Oliveira and L. H. Mattoso, Cellulose, 2010, 17, 595606.

53 F. Bettaieb, O. Nechyporchuk, R. Khiari, M. F. Mhenni, A. Dufresne and M. N. Belgacem, Carbohydr. Polym., 2015, 134, 664-672.

54 X. He, Q. Xiao, C. Lu, Y. Wang, X. Zhang, J. Zhao, W. Zhang, X. Zhang and Y. Deng, Biomacromolecules, 2014, 15, 618627.

55 X. Li, D. Yuan, J. Zhang, Z. Lin and X. Zhang, PLoS One, 2013, 8, e54444.

56 Q. Liu, J. Li, Y. Zhao, Y. Zhou and C. Li, Mater. Lett., 2015, 138, 89-91.

57 P. Preethi and G. B. Murthy, Agrotechnology, 2013, 8(S11), 2. 58 S. F. Souza, A. L. Leao, J. H. Cai, C. Wu, M. Sain and B. M. Cherian, Mol. Cryst. Liq. Cryst., 2010, 522, 42-342.

59 S. Hooshmand, Y. Aitomäki, N. Norberg, A. P. Mathew and K. Oksman, ACS Appl. Mater. Interfaces, 2015, 7, 1302213028.

60 P. Khawas and S. C. Deka, Carbohydr. Polym., 2015, 1-26.

61 W. Chen, H. Yu, Y. Liu, P. Chen, M. Zhang and Y. Hai, Carbohydr. Polym., 2011, 83, 1804-1811.

62 P. C. Tischer, M. R. Sierakowski, H. Westfahl Jr and C. A. Tischer, Biomacromolecules, 2010, 11, 1217-1224.

63 F. M. Pelissari, M. M. Andrade-Mahecha, P. J. Sobral and F. C. Menegalli, Starch/Staerke, 2012, 64, 382-391.

64 H. Tibolla, F. M. Pelissari and F. C. Menegalli, LWT-Food Sci. Technol., 2014, 59, 1311-1318.

65 H. Sehaqui, S. Morimune, T. Nishino and L. A. Berglund, Biomacromolecules, 2012, 13, 3661-3667.

66 T. Saito, R. Kuramae, J. Wohlert, L. A. Berglund and A. Isogai, Biomacromolecules, 2013, 14, 248-253.

67 M. Bergenstråhle, L. A. Berglund and K. Mazeau, J. Phys. Chem. B, 2007, 111, 9138-9145.

68 N. Butchosa and Q. Zhou, Cellulose, 2014, 21, 4349-4358.

69 A. Kentaro, S. Iwamoto and H. Yano, Biomacromolecules, 2007, 8(10), 3276-3278.

70 W. Stelte and A. R. Sanadi, Ind. Eng. Chem. Res., 2009, 48, 11211-11219.

71 K. Abe, S. Iwamoto and H. Yano, Biomacromolecules, 2007, 8, 3276-3278.

72 H. Ma, B. Zhou, H. S. Li, Y. Q. Li and S. Y. Ou, Carbohydr. Polym., 2011, 84, 383-389.

73 H. Yano, S. Sasaki, M. Shams and K. Abe, Adv. Opt. Mater., 2014, 2, 231-234.

74 C. Terenzi, K. Prakobna, L. A. Berglund and L. Furó, Biomacromolecules, 2015, 16, 1506-1515.

75 S. Galland, Y. Leterrier, T. Nardi, C. J. Plummer, J. A. Månson and L. A. Berglund, J. Appl. Polym. Sci., 2014, 131, 16.

76 G. Gellerstedt and I. Pettersson, J. Wood Chem. Technol., 1982, 2, 231-250.
77 X. Z. Zhang, R. C. Francis, D. B. Dutton and R. T. Hill, J. Wood Chem. Technol., 1998, 18, 253-266.

78 A. S. Jaaskelainen, T. Tapanila and K. Poppius-Levlin, J. Wood Chem. Technol., 2000, 20, 43-59.

79 J. Zhao, W. Zhang, W. Zhang, X. Zhang, C. Lu and Y. Deng, Carbohydr. Polym., 2013, 97, 695-702.

80 F. Ansari, M. Skrifvars and L. Berglund, Compos. Sci. Technol., 2015, 117, 298-306.

81 B. Atanu, B. C. Saha, J. W. Lawton, R. L. Shogren and J. L. Willett, Carbohydr. Polym., 2006, 64, 134-137.

82 J. O. Wiiiam, S. Justin, H. I. Syed, M. G. Gregory, E. G. Mara and F. R. Jean, J. Polym. Environ., 2005, 13, 301-306.

83 Z. Xu, Q. H. Wang, Z. Jiang, X. X. Yang and Y. Z. Ji, Biomass Bioenergy, 2007, 31, 162-167.

84 J. Zhao, X. Z. Li and Y. B. Qu, Bioresour. Technol., 2006, 97, 1470-1476.

85 C. Cara, E. Ruiz, M. Ballesteros, P. Manzanares, M. J. Negro and E. Castro, Fuel, 2008, 87, 692-700.

86 A. C. Leung, E. Lam, J. Chong, S. Hrapovic and J. H. Luong, J. Nanopart. Res., 2013, 15, 1-24.

87 E. Kalita, B. K. Nath, P. Deb, F. Agan, R. Md. Islam and K. Saikia, Carbohydr. Polym., 2015, 122, 308-313.

88 B. Nasri-Nasrabadi, M. Mehrasa, M. Rafienia, S. Bonakdar, T. Behzad and S. Gavanji, Carbohydr. Polym., 2014, 108, 232-238.

89 A. Alemdar and M. Sain, Compos. Sci. Technol., 2008, 68, 557-565.

90 S. Elanthikkal, U. Gopalakrishnapanicker, S. Varghese and J. T. Guthrie, Carbohydr. Polym., 2010, 80, 852-859.

91 H. B. Bettaieb, M. Esguerra, D. Delbro, B. Risberg and P. Gatenholm, J. Tissue Eng. Regener. Med., 2008, 2, 320-330.

92 H. Sehaqui, A. Mautner, U. P. Larraya, N. Pfenninger, P. Tingaut and T. Zimmermann, Carbohydr. Polym., 2016, 136, 334-340.

93 D. Theng, G. Arbat, M. Delgado-Aguilar, F. Vilaseca, B. Ngo and P. Mutjé, Ind. Crops Prod., 2015, 76, 166-173.

94 K. Y. Lee, G. Buldum, A. Mantalaris and A. Bismarck, Macromol. Biosci., 2014, 14, 10-32.

95 B. V. Mohite and S. V. Patil, J. Biomater. Sci., Polym. Ed., 2014, 25, 2053-2065.

96 J. Fang, S. Kawano, K. Tajima and T. Kondo, Biomacromolecules, 2015, 16, 3154-3160.

97 S. Gonçalves, J. Padrão, I. P. Rodrigues, J. P. Silva, V. Sencadas, S. Lanceros-Mendez, H. Girão, F. Dourado and L. R. Rodrigues, Biomacromolecules, 2015, 16, 13411351.

98 F. Quero, M. Nogi, K. Y. Lee, G. V. Poel, A. Bismarck, A. Mantalaris, H. Yano and S. J. Eichhorn, ACS Appl. Mater. Interfaces, 2010, 3, 490-499.

99 R. T. Olsson, R. Kraemer, A. Lopez-Rubio, S. Torres-Giner, M. J. Ocio and J. M. Lagarón, Macromolecules, 2010, 43, 4201-4209.

100 K. Y. Lee, J. J. Blaker and A. Bismarck, Compos. Sci. Technol., 2009, 69, 2724-2733.

101 H. Bäckdahl, M. Esguerra, D. Delbro, B. Risberg and P. Gatenholm, J. Tissue Eng. Regener. Med., 2008, 2, 320-330. 102 C. Yang and D. Li, Mater. Lett., 2015, 155, 78-81. 
103 F. Wang and D. Li, Mater. Lett., 2015, 158, 119-122.

104 Z. Zhang, J. Zhang, X. Zhao and F. Yang, Carbon, 2005, 95, 552-559.

105 J. Wang, X. Lu, P. F. Ng, K. I. Lee, B. Fei, J. H. Xin and W. Jian-yong, J. Colloid Interface Sci., 2015, 440, 32-38.

106 J. Fu, D. Li, G. Li, F. Huang and Q. Wei, J. Electroanal. Chem., 2015, 738, 92-99.

107 Y. Jiazhi, L. Xiaoli, H. Liyonga and S. Dongping, Chin. J. Chem. Eng., 2013, 21, 1419-1424.

108 M. Gopiraman, H. Bang, G. Yuan, C. Yin, S. Kyung-Hun, J. S. Lee, I. M. Chung, R. Karvembu and I. S. Kim, Carbohydr. Polym., 2015, 132, 554-564.

109 L. Tian, S. Zi-qiang, W. Jian-quan and G. Mu-jia, Chem. Eng. J., 2015, 260, 818-825.

110 J. Wang, X. Lu, P. F. Ng, K. I. Lee, B. Fei, J. H. Xin and W. Jian-yong, J. Colloid Interface Sci., 2015, 440, 32-38.

111 H. Wang, E. Zhu, J. Yang, P. Zhou, D. Sun and W. Tang, J. Phys. Chem. C, 2012, 116, 13013-13019.

112 W. Hu, S. Chen, Z. Yang, L. Liu and H. Wang, J. Phys. Chem. $B, 2011,115,8453-8457$.

113 Z. Lin, Z. Guan and Z. Huang, Ind. Eng. Chem. Res., 2013, 52, 2869-2874.

114 R. Hobzova, M. Duskova-Smrckova, J. Michalek, E. Karpushkin and P. Gatenholm, Polym. Int., 2012, 61, 1193-1201.

115 M. Nogi and H. Yano, Adv. Mater., 2008, 20, 1849-1852.

116 F. Kramer, D. Klemm, D. Schumann, N. Hebler, F. Wesarg, W. Fried and D. Stadermann, Macromol. Symp., 2006, 244, 136-148.

117 L. E. Millon and W. K. Wan, J. Biomed. Mater. Res., Part B, 2006, 79, 245-253.

118 E. E. Brown and M. P. Laborie, Biomacromolecules, 2007, 8, 3074-3081.

119 P. Zhou, H. Wang, J. Yang, J. Tang, D. Sun and W. Tang, Ind. Eng. Chem. Res., 2012, 51, 5743-5748.

120 S. Ifuku, M. Tsuji, M. Morimoto, H. Saimoto and H. Yano, Biomacromolecules, 2009, 10, 2714-2717.

121 M. Chen, H. Kang, Y. Gong, J. Guo, H. Zhang and R. Liu, ACS Appl. Mater. Interfaces, 2015, 7, 21717-21726.

122 L. F. Chen, Z. H. Huang, H. W. Liang, H. L. Gao and S. H. Yu, Adv. Funct. Mater., 2014, 24, 5104-5111.

123 P. Chen, Y. S. Yun, H. Bak, S. Y. Cho and H. J. Jin, Mol. Cryst. Liq. Cryst., 2010, 519, 69-78.

124 P. Liu, K. Oksman and A. P. Mathew, J. Colloid Interface Sci., 2016, 464, 175-182.

125 W. Meiling, G. Meng, Q. Huang and Y. Qian, Environ. Sci. Technol., 2012, 46, 367-373.

126 M. Snyder, Z. Bo, R. Moon, R. Jean-Christophe and L. Stanciu, J. Colloid Interface Sci., 2013, 399, 92-98.

127 M. Stephen, N. Catherine, M. Brenda, K. Andrew, P. Leslie and G. Corrine, J. Hazard. Mater., 2011, 192, 922-927.

128 X. He, L. Cheng, Y. Wang, J. Zhao, W. Zhang and C. Lu, Carbohydr. Polym., 2014, 111, 683-687.

129 H. Sai, L. Xing, J. Xiang, L. Cui, J. Jiao, C. Zhao, Z. Li and F. Li, J. Mater. Chem. A, 2013, 1, 7963-7970.
130 B. Nasri-Nasrabadi, M. Mehrasa, M. Rafienia, S. Bonakdar, T. Behzad and S. Gavanji, Carbohydr. Polym., 2014, 108, 232-238.

131 J. Zhang, P. Chang, C. Zhang, G. Xiong, H. Luo, Y. Zhu, K. Ren, F. Yao and Y. Wan, React. Funct. Polym., 2015, 9192, 100-107.

132 S. Chahal, F. S. Hussain and M. B. Yusoff, Procedia Eng., 2013, 53, 683-688.

133 K. Qiao, Y. Zheng, S. Guo, J. Tan, X. Chen, J. Li, D. Xu and J. Wang, Compos. Sci. Technol., 2015, 118, 47-54.

134 Z. Aytac, H. S. Sen, E. Durgun and T. Uyar, Colloids Surf., B, 2015, 128, 331-338.

135 P. Opanasopit, W. Sila-on, T. Rojanarata and T. Ngawhirunpat, Pharm. Dev. Technol., 2013, 18, 11401147.

136 R. Andrade, O. Skurtys and F. Osorio, LWT-Food Sci. Technol., 2015, 61, 422-429.

137 S. H. Othman, Agric. Agric. Sci. Procedia, 2014, 2, 296-303.

138 S. V. Vijayendra and T. R. Shamala, Crit. Rev. Biotechnol., 2014, 1-20.

139 X. Z. Tang, P. Kumar, S. Alavi and K. P. Sandeep, Crit. Rev. Food Sci. Nutr., 2012, 52, 426-442.

140 B. Ghanbarzadeh, S. A. Oleyaei and H. Almasi, Crit. Rev. Food Sci. Nutr., 2015, 55, 1699-1723.

141 D. M. Panaitescu, A. N. Frone, M. Ghiurea and L. Chiulan, Ind. Crops Prod., 2015, 70, 170-177.

142 H. M. De Azeredo, Food Res. Int., 2009, 42, 1240-1253.

143 C. Yang, C. Chen, Y. Pan, S. Li, F. Wang, J. Li, N. Li, X. Li, Y. Zhang and D. Li, Electrochim. Acta, 2015, 182, 264-271.

144 S. Tidjarat, W. Winotapun, P. Opanasopit, T. Ngawhirunpat and T. Rojanarata, J. Chromatogr. A, 2014, 1367, 141-147.

145 T. Rojanarata, S. Plianwong, K. Su-uta, P. Opanasopit and T. Ngawhirunpat, Talanta, 2013, 115, 208-213.

146 F. Jiang and H. You-Lo, Carbohydr. Polym., 2015, 122, 60-68. 147 H. Yousefi, T. Nishino, M. Faezipour, G. Ebrahimi and A. Shakeri, Biomacromolecules, 2011, 12, 4080-4085.

148 E. Tamahkar, T. Kutsal and A. Denizli, Process Biochem., 2015, 50(12), 2289-2297.

149 S. Bottan, F. Robotti, P. Jayathissa, A. Hegglin, N. Bahamonde, J. A. Heredia-Guerrero, I. S. Bayer, A. Scarpellini, H. Merker, N. Lindenblatt, D. Poulikakos and A. Ferrari, ACS Nano, 2015, 9, 206-219.

150 L. Liu, D. He, W. Guang-Sheng and Y. Shu-Hong, Langmuir, 2011, 27, 7199-7206.

151 M. Schreiber, S. Vivekanandhan, A. K. Mohanty and M. Misra, ACS Sustainable Chem. Eng., 2015, 3, 33-41.

152 T. Stylianopoulos, M. Kokonou, S. Michael, A. Tryfonos, C. Rebholz, A. D. Odysseos and C. Doumanidis, J. Biomed. Mater. Res., Part B, 2012, 100, 2222-2230.

153 A. K. Bledzki, A. A. Mamun, M. Lucka-Gabor and V. S. Gutowski, eXPRESS Polym. Lett., 2008, 2, 413-422.

154 G. L. Louis and B. A. K. Andrews, Text. Res. J., 1987, 57, 339345.

155 A. Thygesen, J. Oddershede, H. Lilholt, A. B. Thompsen and K. Stahl, Cellulose, 2005, 12, 563-576.

156 J. D. Megiatto Jr, Fibras de Sisal: Estudo de propriedades e modificações químicas visando a aplicação em compósitos 
de matriz fenólica, Ph.D. thesis, Federal University of São Carlos, Brazil, 2006.

157 K. Devarayan and K. Byoung-Suhk, Sens. Actuators, B, 2015, 209, 281-286.

158 J. Matulevicius, L. Kliucininkas, T. Prasauskas, D. Buivydiene and D. Martuzevicius, J. Aerosol Sci., 2016, 92, 27-37.

159 C. Zhijiang, X. Yi, Y. Haizheng, J. Jia and Y. Liu, Mater. Sci. Eng., C, 2016, 58, 757-767.

160 F. A. Aouada, M. R. De Moura, W. J. Orts and L. H. C. Mattoso, J. Agric. Food Chem., 2011, 59, 9433-9442.

161 S. M. Musyoka, J. C. Ngila and B. B. Mamba, Phys. Chem. Earth, 2013, 66, 45-50.

162 V. Kuzmenko, O. Naboka, H. Staaf, M. Haque, G. Goransson, P. Lundgren, P. Gatenholm and P. Enoksson, Mater. Chem. Phys., 2015, 160, 59-65.

163 M. Wang, G. Meng, Q. Huang and Y. Qian, Environ. Sci. Technol., 2012, 46, 367-373.

164 F. Ahmed, S. Saleemi, Z. Khatri, M. I. Abro and K. Ick-Soo, Carbohydr. Polym., 2015, 115, 388-393.

165 P. P. S. Lacerda, A. M. M. V. Barros-Timmons, C. S. R. Freire, A. J. D. Silvestre and C. P. Neto, Biomacromolecules, 2013, 14, 2063-2073.

166 W. D. Ding, R. K. M. Chu, L. H. Mark, C. B. Park and M. Sain, Eur. Polym. J., 2015, 71, 231-247.

167 K. Benhamou, H. Kaddami, A. Magnin, A. Dufresne and A. Ahmad, Carbohydr. Polym., 2015, 122, 202-211.

168 K. Prakobna, C. Terenzi, Q. Zhou, I. Furó and L. A. Berglund, Carbohydr. Polym., 2015, 125, 92-102.

169 M. Babaee, M. Jonoobi, Y. Hamzeh and A. Ashori, Carbohydr. Polym., 2015, 132, 1-8.
170 A. Lavoratti, L. C. Scienza and A. J. Zattera, Carbohydr. Polym., 2016, 136, 955-963.

171 K. Prakobna, S. Galland and L. A. Berglund, Biomacromolecules, 2015, 16, 904-912.

172 E. Tamahkar, T. Kutsal and A. Denizli, Process Biochem., 2015, 50(12), 2289-2297.

173 N. Volk, R. He and R. Magniez, Eur. Polym. J., 2015, 72, 270281.

174 A. N. Frone, C. A. Nicolae, R. A. Gabor and D. Panaitescu, Polym. Degrad. Stab., 2015, 121, 385-397.

175 A. Abdulkhani, J. Hosseinzadeh, A. Ashori, S. Dadashi and Z. Takzare, Polym. Test., 2014, 35, 73-79.

176 H. Almasi, B. Ghanbarzadeh, J. Dehghannya, A. A. Entezami and A. K. Asl, Food Packaging and Shelf Life, 2015, 5, 21-31.

177 C. Zhou, R. Chu, R. Wu and Q. Wu, Biomacromolecules, 2011, 12, 2617-2625.

178 N. Chitpong and M. S. Husson, J. Membr. Sci., 2017, 523, 418-429.

179 M. L. Foresti, A. Vázquez and B. Boury, Carbohydr. Polym., 2017, 157, 447-467.

180 X. Kang, P. Sun, S. Kuga, C. Wang, Y. Zhao, M. Wu and Y. Huang, ACS Sustainable Chem. Eng., 2017, 5(3), 25292534.

181 Z. Wang, C. Crandall, V. L. Prautzsch, R. Sahadevan, T. J. Menkhaus and H. Fong, ACS Appl. Mater. Interfaces, 2017, 9(4), 4272-4278.

182 N. N. Bui and J. R. McCutcheon, Environ. Sci. Technol., 2013, 47(3), 1761-1769. 